
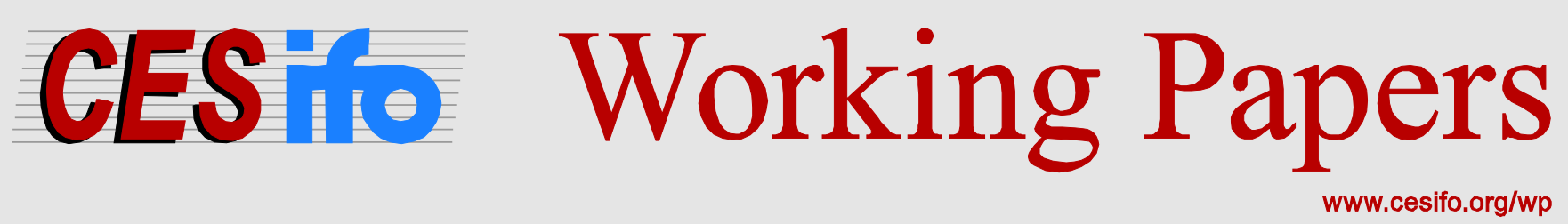

\title{
Carbon Tariffs: An Analysis of the Trade, Welfare and Emission Effects
}

\author{
Mario Larch \\ Joschka Wanner
}

CESIFO WORKING PAPER NO. 4598

CATEGORY 8: TRADE POLICY

ORIGINAL VERSION: JANUARY 2014

THIS VERSION: FEBRUARY 2015

An electronic version of the paper may be downloaded

- from the SSRN website:

- from the RePEc website:

- from the CESifo website:

WWW.SSRN.com

www.RePEc.org

www.CESifo-group.org/wp

\section{CESifo}




\title{
Carbon Tariffs: An Analysis of the Trade, Welfare and Emission Effects
}

\begin{abstract}
Carbon tariffs are one prominently discussed climate policy. The proponents stress the carbon tariffs' ability to restore competitiveness, avoid carbon leakage, and reduce world carbon emissions. We analyze the effects of carbon tariffs on trade, welfare, and carbon emissions in a structural gravity model. We find that the introduction of carbon tariffs reduces welfare in most countries and the effect tends to be most pronounced in developing countries. Further, carbon emissions are massively shifted from these countries to industrialized countries and world carbon emissions decrease by 0.83 percent, with a bootstrapped $95 \%$ confidence interval of $[-0.92,-0.80]$. In our two-sector, two-factor gravity model, we are able to decompose the emission changes into scale, composition, and technique effects. While for individual countries composition accounts for 73 percent of the change on average, two thirds of the world reduction are due to the world scale effect.
\end{abstract}

JEL-Code: F140, F180, Q560.

Keywords: carbon tariffs, climate policy, gravity model.

\author{
Mario Larch \\ University of Bayreuth \\ Universitätsstraße 30 \\ Germany - 95447 Bayreuth \\ mario.larch@uni-bayreuth.de
}

\author{
Joschka Wanner \\ University of Bayreuth \\ Universitätsstraße 30 \\ Germany - 95447 Bayreuth \\ joschka.wanner@uni-bayreuth.de
}

February 2, 2015

Funding from the DFG under project 592405 is gratefully acknowledged. We thank Rahel Aichele, Gabriel Felbermayr, Carol McAusland, Alejandro Riaño, João Santos Silva, Yoto Yotov, and participants at the European Trade Study Group 2013, the Goettinger Workshop “Internationale Wirtschaftsbeziehungen” 2014, the GEP Postgraduate Conference 2014 and the Conference of the European Economic Association 2014 for helpful comments. We also thank Eva-Maria Rieger and Felix Stips for excellent research assistance. 


\section{Introduction}

The struggle against anthropogenic climate change is one of the most urgent tasks of humankind in the 21st century. A big strand of economic literature has evolved around the question of how to reduce global greenhouse gas (GHG) emissions in an efficient way 1 It is obvious that a first-best solution would involve the participation of all countries, including developing nations (see for example Branstetter and Pizer, 2014). But the past United Nations climate conferences have made it abundantly clear that an effective international agreement is unlikely to be implemented in the near future. Instead, national and/or regional initiatives will presumably prevail. The lack of international coordination raises questions concerning the relationship of national (or regional) climate policies and international trade. Unilateral emission reductions can for example be partly offset by resulting increases in other countries, i.e. emissions can be shifted via international trade, a phenomenon known as carbon leakage (see Felder and Rutherford, 1993).

One possible measure against carbon leakage is the introduction of carbon tariffs. With carbon tariffs, countries with a stricter climate policy would impose an import tariff on goods from countries with laxer regulation (or lower carbon prices), based on the amount of carbon emissions embodied in the good. Carbon tariffs are very prominently discussed in the environmental policy debate. For example, the House of Representatives in the USA released a bill in 2009 that enables the introduction of carbon tariffs from 2020 onwards in some carbon intensive sectors (see for example Krugman, 2009a). In Europe, French politicians have repeatedly called for carbon tariffs by the European Union, most prominently the former President Sarkozy in 2009 (see for example Krugman, 2009b). Claims for carbon tariffs also received prominent academic support. Nobel laureate Paul Krugman (2009a b) argues for carbon tariffs in his New York times column by highlighting the fact that trade policy may

\footnotetext{
${ }^{1}$ See Aldy, Krupnick, Newell, Parry, and Pizer (2010) for a survey of the respective research.
} 
indeed be a good tool in the case of non-economic objectives such as carbon emissions that do not respect national borders. This policy measure is the thematic object of investigation of this work.

As carbon tariffs have a strong international perspective, it is natural to analyze the effects in a trade model typically used to evaluate trade policies. We therefore use as a starting point an empirically very successful structural empirical trade model, which explains trade flows by country sizes, distances and multilateral resistance terms, which capture the embedding of a country into the world economy. These models are known as structural gravity models (see for example, Eaton and Kortum (2002) and Anderson and van Wincoop (2003), as well as the survey by Head and Mayer (2014)). Costinot and Rodríguez-Clare (2014) nicely summarize the advantages of structural gravity models: i) they are better micro-founded than other quantitative work, like many Computational General Equilibrium (CGE) models, ii) they provide a close link between the theory and the data by estimating the parameters from the same model and data as are used for the counterfactual analysis, and iii) they are still small enough to understand the driving mechanisms and do not hide important mechanisms behind hundreds of equations.

As we want to investigate the effects of carbon tariffs on trade, welfare and emissions, we have to adopt existing structural trade models to incorporate important aspects of carbon emissions. First, we add a production structure that uses energy as an input. Second, we allow for emissions as a side output of production related to the amount of energy employed. Third, we allow for two sectors to distinguish between a sector of high and a sector of low carbon emission intensity. Fourth, we introduce revenue-generating tariffs in order to implement carbon tariffs. With the resulting structural model it is possible to evaluate ex ante the effects of the introduction of carbon tariffs. Importantly, our model structure allows a decomposition of the emission effects into scale, composition, and technique effect as first proposed by Grossman and Krueger (1993) and formalized by Copeland and Taylor (1994). While there are already 
some studies quantifying the carbon emission effects of carbon tariffs (see for a discussion section 2), to the best of our knowledge we are the first to empirically implement the decomposition as in Copeland and Taylor (2003) based on a structural two-sector, multi-country framework. In such a framework, the decomposition helps to understand the cross-country differences of the effects as well as the effects on the world as a whole.

Using our estimable structural model, we find that the introduction of carbon tariffs reduces trade flows and welfare for most countries, and most strongly for developing countries. Concerning carbon emissions, we indeed see a shift of carbon emissions from low carbon tax countries to high carbon tax countries. Hence, carbon tariffs reduce carbon leakage. Our analysis further reveals that world carbon emissions would decrease by 0.83 percent by introducing carbon tariffs. The bootstrapped $95 \%$ confidence interval of $[-0.92$, -0.80] for this counterfactual calculation shows that the decrease is statistically significant. About two thirds of this reduction can be attributed to a world scale effect (-0.58 percent with bootstrapped $95 \%$ confidence interval [-0.63, $-0.55]$ ), while the last third results from changes in the composition of production across countries $(-0.28$ percent with bootstrapped $95 \%$ confidence interval $[-0.40,-0.20])$.

The rest of this work proceeds as follows: Section 2 introduces carbon leakage and the concept of carbon tariffs in some more detail, also giving a short overview of other work in the area. In section 3 we develop a structural gravity model in the vein of Anderson and van Wincoop (2003), incorporating a sectoral structure, a two-factor production function and non-resource consuming, revenue-generating tariffs. We also introduce the decomposition of the emission effect in this framework. In section 4 we derive a stochastic version of the developed model, describe the methods used for its estimation and briefly explain how the remaining model parameters are obtained. Section 5 presents the data sources and some descriptive statistics. In section 6 firstly the regression results for the gravity equation are shown. Then, the results obtained for 
the counterfactual introduction of carbon tariffs are presented. In section 7 we develop a model extension incorporating a production structure for energy. Section 8 concludes.

\section{Carbon Leakage and Carbon Tariffs}

The relationship of carbon policy and international trade has been of major interest in the last years. One phenomenon that has been discussed in this context is carbon leakage. Carbon leakage arises if stricter climate policy and a resulting reduction of emissions in one country (or region, such as e.g. the European Union) leads to an increase of carbon emissions elsewhere. This can mainly occur due to two reasons. Firstly, a higher carbon price (via a carbon tax, tradable certificates or simply stricter regulation) makes goods from the country implementing the policy relatively more expensive. This can lead to a shift of carbon emission intensive production to countries with laxer regulation or lower carbon prices and hence increase emissions in these countries (see for example Felder and Rutherford, 1993). Secondly, a higher carbon price can lead to a lower demand for energy in the countries imposing the regulation. This could lead to falling world market prices for energy and hence lead to a more emission-intensive production in other countries (Sinn, 2008). This mechanism is called energy-market leakage (see for example McAusland and Najjar, forthcoming). We will focus on the former type of carbon leakage in the base model. The model extension in section 7 will additionally incorporate energy-market leakage effects.

Several empirical studies have investigated the extent of carbon leakage. For example, Aichele and Felbermayr (2012, forthcoming) conduct ex-post analyses of the Kyoto Protocol's ability to reduce world carbon emissions. They find strong evidence that the Kyoto Protocol led to carbon leakage. In fact, the reductions in the committed countries may have been completely offset (or possibly even overcompensated) by increases in other countries. On 
the other hand, Chan, Li, and Zhang (2013) investigate the effects of the European Union emission trading scheme and find little evidence for carbon leakage.

A second approach in the literature is the use of computable general equilibrium (CGE) models. Burniaux and Oliveira Martins (2012) give a good overview here. Estimated leakage rates (i.e. the percentage part of domestic emission reductions that is offset by foreign increases) in these models range between two and 20 percent in most cases, but can also go up as high as 100 percent (see for example Babiker, 2005). Another approach that, just as CGE models, allows ex ante investigations of policy scenarios in an international trade context is the use of structural gravity models. Aichele (2013) explicitly investigates carbon leakage in a one-sector Anderson and van Wincoop (2003)type framework which she augments with a multi-factor production structure. She investigates several counterfactual scenarios, finding for example a leakage rate of 10 percent for an increase of the EU emission allowance price to 15 US\$. Besides Aichele (2013), Egger and Nigai (2012, forthcoming) use structural gravity models in a similar context. In both cases, these authors employ an Eaton and Kortum (2002)-type framework. Egger and Nigai (2012) analyze the implications of the Copenhagen Accord. Based on the pledges countries made in the Accord, required carbon prices are calculated and implemented in different counterfactual scenarios. One of their most important findings is again interesting in the carbon leakage context: welfare losses from stricter climate policies are found to be minimized if implemented in an internationally cooperative way. Egger and Nigai (forthcoming) include an energy sector in their model and compare different policy measures meant to reduce a country's energy demand.

Even though its extent remains a matter of scientific debate, carbon leakage is likely to at least reduce the effectiveness of unilateral climate policies. One measure that could be taken in order to reduce carbon leakage is the introduction of carbon tariffs. Leaving the question of legal and practical fea- 
sibility aside $2^{2}$ questions arise of how these tariffs would influence trade flows, welfare, and carbon emissions. This is mainly investigated within the framework of computable general equilibrium models. For example, Elliott, Foster, Kortum, Munson, Pérez Cervantes, and Weisbach (2010) find that accompanying a higher carbon tax in some countries with full border tax adjustment (i.e. a combination of import tariffs and export subsidies) eliminates carbon leakage but has no noteworthy effect on world carbon emissions. Elliott, Foster, Kortum, Khun Jush, Munson, and Weisbach (2013) investigate a similar scenario without export subsidies and find that carbon tariffs reduce world carbon emissions. Böhringer, Carbone, and Rutherford (2011) also find that carbon tariffs shift emissions back from developing to richer countries, i.e. reduce carbon leakage, but without reducing world emissions. They argue that the main effect of introducing carbon tariffs is to shift the welfare costs of climate policy to developing countries. Babiker and Rutherford (2005) compare different accompanying measures for the Kyoto Coalition countries' abatement policies. They also find that carbon tariffs partly push the abatement costs to non-Coalition countries, minimizing the Coalition's welfare costs, and therefore are more attractive than alternative measures such as voluntary export restraints.

In the gravity framework, one of the policy measures investigated by Egger and Nigai (forthcoming) are import tariffs. They investigate tariffs as a mean to reduce domestic emissions by imposing a tariff on imported energy inputs, but do not consider carbon tariffs. Hence, to the best of our knowledge, carbon tariffs have not yet been analyzed within a structural gravity model. Besides closely linking theory and data, this has the additional advantage of allowing a decomposition of the carbon tariffs' effects on the scale, composition, and technique of production. This is the aim of our analysis.

\footnotetext{
${ }^{2}$ For a short treatment of the legal issues in the WTO context and practical implementation issues, see Branstetter and Pizer 2014, pp. 26-27 and pp. 34-35, respectively).
} 


\section{A Multi-Sector Gravity Model with Tariffs}

\subsection{Trade Flows}

In this section, we develop a gravity model in the vein of Anderson and van Wincoop (2003). Their model aggregates over all sectors. As the aim of this work is to investigate the effects of a policy measure that will influence sectors differently according to their carbon intensities, this level of aggregation is inappropriate in the given context. We therefore allow for a sectoral structure in the model, following Anderson and Yotov (2010), Caliendo and Parro (2015) and most closely the approach of Egger, Larch, and Staub (2012), who introduce a sectoral structure into a Krugman (1980)-type gravity model.

Let us assume there are 2 sectors $(l)$ in each of $N$ countries, a clean sector $(l=C)$ and a dirty sector $(l=D)$. We refer to a sector as dirty or clean if it is carbon-emission intensive in production or not, respectively, following Copeland and Taylor (2003). This bisectoral structure allows us to analytically decompose the change in emissions into scale, composition, and technique effects.

Following Armington (1969), goods within one sector are differentiated by country of origin and each country produces one variety per sector. The utility of the representative consumer from consumption in a specific sector is given by a constant elasticity of substitution (CES) utility function:

$$
U_{l}^{j}=\left[\sum_{i=1}^{N}\left(\beta_{l}^{i}\right)^{\frac{1-\sigma_{l}}{\sigma_{l}}}\left(q_{l}^{i j}\right)^{\frac{\sigma_{l}-1}{\sigma_{l}}}\right]^{\frac{\sigma_{l}}{\sigma_{l}-1}}
$$

where $\beta_{l}^{i}$ is a positive, country- and sector-specific distribution parameter (which can for example be interpreted as representing quality differences), $q_{l}^{i j}$ is the amount of goods from country $i$ in sector $l$ that the representative consumer in country $j$ buys, and $\sigma_{l}$ is the elasticity of substitution. CES utility functions have the desirable property of accounting for a "love of variety" of the consumers, i.e. for a given consumption level, a higher utility level is 
achieved if more different varieties are consumed.

The utility received from consumption in the different sectors is combined to give the total utility of the representative consumer by a Cobb-Douglas function $U^{j}=\prod_{l \in\{C, D\}}\left(U_{l}^{j}\right)^{\gamma_{l}^{j}}$, where $\sum_{l \in\{C, D\}} \gamma_{l}^{j}=1$. Sectoral expenditure in country $j$ is given by $\mathfrak{X}_{l}^{j}=\gamma_{l}^{j} \mathfrak{X}^{j}=\sum_{i=1}^{N} p_{l}^{i j} q_{l}^{i j}$, where $p_{l}^{i j}$ is the price in country $j$ for goods from country $i$. A country's total income is given by the sum of its sectoral productions and its tariff revenues:

$$
Y^{j}=\sum_{l \in\{C, D\}} Y_{l}^{j}+\sum_{l \in\{C, D\}} \sum_{i=1}^{N}\left(\tau_{l}^{i j}-1\right) X_{l}^{i j},
$$

where $\tau_{l}^{i j}$ is one plus the ad valorem tariff rate and $X_{l}^{i j}$ is the value of exports from country $i$ to country $j$ in sector $l$.

We assume multilaterally balanced trade at the country level. This implies that total expenditure equals total income in each country. Summing expenditures over sectors yields the corresponding expression $Y^{j}=\mathfrak{X}^{j}=$ $\sum_{l \in\{C, D\}} \mathfrak{X}_{l}^{j}=\sum_{l \in\{C, D\}} \sum_{i=1}^{N} p_{l}^{i j} q_{l}^{i j}$, which represents the budget constraint for country $j$. The representative consumer in $j$ hence maximizes $U^{j}$ subject to this budget constraint. This determines the demand in country $j$ for goods from sector $l$ from country $i$ :

$$
q_{l}^{i j}=\left(\frac{\beta_{l}^{i} p_{l}^{i j}}{P_{l}^{j}}\right)^{-\sigma_{l}}\left(\frac{\beta_{l}^{i} \mathfrak{X}_{l}^{j}}{P_{l}^{j}}\right)
$$

where $P_{l}^{j}$ is the ideal price index, given by

$$
P_{l}^{j}=\left[\sum_{i=1}^{N}\left(\beta_{l}^{i} p_{l}^{i j}\right)^{1-\sigma_{l}}\right]^{\frac{1}{1-\sigma_{l}}}
$$

Assuming (sector-specific) iceberg transport costs, the price consumers in $j$ pay for imports from $i$ can be restated as $p_{l}^{i j}=T_{l}^{i j} \tau_{l}^{i j} p_{l}^{i}$, where $T_{l}^{i i}=1, T_{l}^{i j} \geq 1$ and trade costs are, in contrast to tariffs, additionally assumed to be symmetric, 
i.e. $T_{l}^{i j}=T_{l}^{j i}$. The value of exports from $i$ to $j$ can then be expressed as

$$
X_{l}^{i j} \equiv p_{l}^{i} q_{l}^{i j} T_{l}^{i j}=\left(\tau_{l}^{i j}\right)^{-\sigma_{l}}\left(\frac{\beta_{l}^{i} p_{l}^{i} T_{l}^{i j}}{P_{l}^{j}}\right)^{1-\sigma_{l}} \mathfrak{X}_{l}^{j}
$$

Goods market clearing ensures that the sectoral production of a country is equal to the world-wide demand for its good $Y_{l}^{i}=\sum_{j=1}^{N} X_{l}^{i j}$. Replacing $X_{l}^{i j}$ by the expression given in equation (5), rearranging to solve for $\left(\beta_{l}^{i} p_{l}^{i}\right)^{1-\sigma_{l}}$, substituting this expression into (5), defining $\theta^{j} \equiv Y^{j} / Y^{W}, \tilde{\theta}_{l}^{i} \equiv Y_{l}^{i} / Y^{W}$, $Y^{W}=\sum_{j=1}^{N} Y^{j}$, and using $\mathfrak{X}_{l}^{j}=\gamma_{l}^{j} \mathfrak{X}^{j}=\gamma_{l}^{j} Y^{j}$ gives an expression that strongly

resembles the well-known expression obtained by Anderson and van Wincoop (2003) and Anderson and Yotov (2010), accounting for tariffs and the sectoral structure:

$$
X_{l}^{i j}=\frac{\gamma_{l}^{j} Y^{j} Y_{l}^{i}}{Y^{W}}\left(\frac{T_{l}^{i j}}{\Pi_{l}^{i} P_{l}^{j}}\right)^{1-\sigma_{l}}\left(\tau_{l}^{i j}\right)^{-\sigma_{l}}
$$

with

$$
\Pi_{l}^{i}=\left[\sum_{j=1}^{N}\left(\frac{T_{l}^{i j}}{P_{l}^{j}}\right)^{1-\sigma_{l}}\left(\tau_{l}^{i j}\right)^{-\sigma_{l}} \gamma_{l}^{j} \theta^{j}\right]^{\frac{1}{1-\sigma_{l}}}
$$

and

$$
P_{l}^{j}=\left[\sum_{i=1}^{N}\left(\frac{T_{l}^{i j} \tau_{l}^{i j}}{\Pi_{l}^{i}}\right)^{1-\sigma_{l}} \tilde{\theta}_{l}^{i}\right]^{\frac{1}{1-\sigma_{l}}} .
$$

$\Pi_{l}^{i}$ and $P_{l}^{j}$ represent so-called outward and inward multilateral resistance terms, respectively, indicating that bilateral trade flows depend on relative trade costs.

\subsection{Introducing a Two-Factor Production Function}

The Anderson and van Wincoop (2003) framework relies on the assumption of an endowment economy. Without a production structure as in an endowment economy, there is no convincing way to include for example energy as an input factor or emissions as a side output into the model. As such features are of great interest in the carbon leakage context, we follow the approach by Aichele (2013) to incorporate a production function that allows for multiple input factors. We will consider two factors, energy and labor, but the production 
function could easily be extended to more factors. As the use of energy is highly correlated with the emission of $\mathrm{CO}_{2}$ (see for example Egger and Nigai, forthcoming), we can include energy into the production function and treat the emissions as a proportional side output. Sectoral production in country $i$ can then be modeled by the following Cobb-Douglas production function with constant returns to scale:

$$
q_{l}^{i}=A_{l}^{i}\left(E_{l}^{i}\right)^{\alpha_{l}^{i}}\left(L_{l}^{i}\right)^{1-\alpha_{l}^{i}}
$$

where $A_{l}^{i}$ is a sector- and country-specific productivity parameter, $E_{l}^{i}$ is the amount of energy used in country $i$ in sector $l, \alpha_{l}^{i}$ is the country- and sectorspecific cost share of energy and $L_{l}^{i}$ is the sectoral labor use.$^{3}$ Labor is assumed to be perfectly mobile between sectors but internationally immobile. For the energy market in our base model, we also follow Aichele (2013) by deviating from the standard factor market assumptions. A country's energy price $e^{i}$ is exogenously given and there is a completely elastic supply of energy at the given price. $4^{45}$ Just as wages, factor income from energy is treated as part of the income of the representative consumer. With this production structure, one can derive expressions for the equilibrium amount of energy and wages which we use in deriving counterfactual expressions. We refer the interested reader to Appendix A.1.

\footnotetext{
${ }^{3}$ As we refrain from including further factors (such as capital or land) into the model, the factor labor should here rather be interpreted as an accumulative factor covering all factors except energy.

${ }^{4}$ Note that this assumption rules out energy-market leakage effects. In order to be able to capture such effects, we develop a model extension incorporating a more elaborate energy market model in section 7 .

${ }^{5}$ An energy price that is held constant may in fact be quite plausible given the important role of the oil market and OPEC's role as a dominant producer therein. OPEC may have incentives to adjust the amount of oil in order to keep the oil price stable. This role of OPEC and its influence on energy-market leakage is analyzed in detail by Böhringer, Rosendahl, and Schneider (2013).
} 


\subsection{Counterfactuals}

An important feature of structural gravity models is that they allow ex-ante evaluations of policies by counterfactual analyses. For the model derived in sections 3.1 and 3.2 , this means that for example the effects of climate policy (associated with a change in $e^{i}$ ), of trade policy (such as the reduction of trade costs via regional trade agreements) or (as will be done in this work) of the introduction of carbon tariffs (a combined climate and trade policy instrument, so to say) on trade flows, welfare and carbon emissions can be investigated. In this section, we will show how to solve the model for counterfactual sectoral GDPs, income, and scaled equilibrium prices and then derive expressions for the counterfactual values of the other variables of interest.

Let the additional subscripts $b$ and $c$ denote the benchmark and the counterfactual cases, respectively. Let us start by rewriting the market clearing condition $Y_{l}^{i}=\sum_{j=1}^{N} X_{l}^{i j}$ for the benchmark case, defining scaled equilibrium prices $\psi_{l, b}^{i}=\left(\beta_{l}^{i} p_{l, b}^{i}\right)^{1-\sigma_{l}}$, inserting the price index (4), and using $\mathfrak{X}_{l, b}^{j}=\gamma_{l}^{j} Y_{b}^{j}$ :

$$
Y_{l, b}^{i}=\psi_{l, b}^{i} \sum_{j=1}^{N} \frac{\left(T_{l, b}^{i j}\right)^{1-\sigma_{l}}\left(\tau_{l, b}^{i j}\right)^{-\sigma_{l}}}{\sum_{k=1}^{N} \psi_{l, b}^{k}\left(T_{l, b}^{k j} \tau_{l, b}^{k j}\right)^{1-\sigma_{l}}} \gamma_{l}^{j} Y_{b}^{j}
$$

Given data for $Y_{l, b}^{i}$ and $Y_{b}^{j}$ and values for $\gamma_{l}^{j}, \sigma_{l}, T_{l, b}^{i j}$ and $\tau_{l, b}^{i j}$, the $2 N$ equations represented by $(10)$ can be solved for the $2 N$ values of the scaled equilibrium prices in the benchmark scenario, $\psi_{l, b}^{i}$.

The most fundamental counterfactual variable is the sectoral GDP, $Y_{l, c}^{i}$. Restating expression 10 for the counterfactual case therefore is a good starting point:

$$
Y_{l, c}^{i}=\psi_{l, c}^{i} \sum_{j=1}^{N} \frac{\left(T_{l, c}^{i j}\right)^{1-\sigma_{l}}\left(\tau_{l, c}^{i j}\right)^{-\sigma_{l}}}{\sum_{k=1}^{N} \psi_{l, c}^{k}\left(T_{l, c}^{k j} \tau_{l, c}^{k j}\right)^{1-\sigma_{l}}} \gamma_{l}^{j} Y_{c}^{j} .
$$

As there are 2 sectors, this is a system of $2 N$ equations. But as there are $5 N$ unknowns $\left(Y_{l, c}^{i}, \psi_{l, c}^{i}\right.$ and $\left.Y_{c}^{i}\right)$, the system is not solvable.

Using equation (2), along with equations (4) and (5), the following addi- 
tional expression can be obtained for a country's counterfactual total income:

$$
Y_{c}^{i}=\sum_{l \in\{C, D\}}\left(Y_{l, c}^{i}+\sum_{j=1}^{N}\left(\tau_{l, c}^{j i}-1\right) \frac{\psi_{l, c}^{j}\left(T_{l, c}^{j i}\right)^{1-\sigma_{l}}\left(\tau_{l, c}^{j i}\right)^{-\sigma_{l}}}{\sum_{k=1}^{N} \psi_{l, c}^{k}\left(T_{l, c}^{k i} \tau_{l, c}^{k i}\right)^{1-\sigma_{l}}} \gamma_{l}^{i} Y_{c}^{i}\right)
$$

This adds $N$ equations to the system. Using the production structure of our model given by equation (9), we can find an expression for the counterfactual change in sectoral GDP, which adds another $2 N$ equations without further unknowns (see Appendix A.2 for details of the derivation):

$$
\left(\frac{\psi_{l, c}^{i}}{\psi_{l, b}^{i}}\right)^{\frac{1}{\sigma_{l}-1}}=\left(\frac{e_{b}^{i}}{e_{c}^{i}}\right)^{\alpha_{l}^{i}}\left(\frac{\sum_{m \in\{C, D\}}\left(1-\alpha_{m}^{i}\right) Y_{m, b}^{i}}{\sum_{m \in\{C, D\}}\left(1-\alpha_{m}^{i}\right) Y_{m, c}^{i}}\right)^{1-\alpha_{l}^{i}}
$$

Equations (11) to 13 represent a system of $5 N$ equations in $5 N$ unkowns. There are data or exogenously set values for $Y_{l, b}^{i}, e^{i}, \sigma_{l}, \gamma_{l}^{i}$ and $\alpha_{l}^{i}$, estimates or exogenously set values for $T_{l, c}^{i j}$ and $\tau_{l, c}^{i j}$, and values for $\psi_{l, b}^{i}$ can be obtained by solving 10 . Hence, the system is solvable for $N$ values of $Y_{c}^{i}$ and $2 N$ values of $Y_{l, c}^{i}$ and $\psi_{l, c}^{i}$ each ${ }^{6}$

The aim of counterfactual analyses in this modeling framework is to evaluate policy scenarios (such as the introduction of carbon tariffs) in terms of their impact on trade flows, welfare (measured as real income) ${ }^{7}$, and carbon emissions. Given the solved values for counterfactual nominal sectoral GDPs, nominal total income, and for the scaled equilibrium prices, these variables can be obtained.

The effect of counterfactual scenarios on trade flows could in general be investigated on a sectoral and bilateral level. As this would imply the depiction

\footnotetext{
${ }^{6}$ Note that in our counterfactual scenario for carbon tariffs, we do not change the estimated trade costs or the carbon price, i.e. $T_{l, b}^{i j}=T_{l, c}^{i j}$ and $e_{b}^{i}=e_{c}^{i}$. We nonetheless stick to the general notation above to show that counterfactual analyses involving exogenous changes in these variables could just as well be conducted in the given framework.

${ }^{7}$ We define welfare by income only and ignore taking into account the level of emissions directly in our welfare function to cleanly distinguish income and emissions. This is in line with the literature studying the carbon emission effects of trade (see for example Burniaux and Oliveira Martins, 2012). The weights given to each of these components in any social welfare function are ultimately a political decision and not part of our analysis. For a discussion of different welfare and GDP concepts see Stiglitz, Sen, and Fitoussi (2010).
} 
of $2 N^{2}$ numbers, we instead only present the effect on a country's aggregate total trade flows. Due to the balanced trade assumption made, it does not make any difference if the percentage change in total imports or total exports is analyzed and the counterfactual percentage changes in a country's trade flows can hence be obtained as

$$
\Delta X^{i} \equiv\left[\frac{\sum_{l \in\{C, D\}} \sum_{j=1}^{N} X_{l, c}^{i j}}{\sum_{l \in\{C, D\}} \sum_{j=1}^{N} X_{l, b}^{i j}}-1\right] \times 100
$$

where the values of $X_{l, b}^{i j}$ and $X_{l, c}^{i j}$ can be obtained using equations (6) to (8) for the benchmark and counterfactual case, respectively.

For evaluating changes in real income, the counterfactual sectoral price indeces are required. These are given by equation (4) and can be reformulated as

$$
P_{l, c}^{i}=\left[\sum_{j=1}^{N}\left(T_{l, c}^{j i} \tau_{l, c}^{j i}\right)^{1-\sigma_{l}} \psi_{l, c}^{j}\right]^{\frac{1}{1-\sigma_{l}}}
$$

Real income is defined as $R^{i}=Y^{i} / P^{i}=Y^{i} / \prod_{l \in\{C, D\}}\left(P_{l}^{i}\right)^{\gamma_{l}^{i}}$. The percentage change of real income is then given by

$$
\Delta R^{i} \equiv\left(\frac{Y_{c}^{i} / P_{c}^{i}}{Y_{b}^{i} / P_{b}^{i}}-1\right) \times 100=\left(\frac{Y_{c}^{i} \prod_{l \in\{C, D\}}\left(P_{l, b}^{i}\right)^{\gamma_{l}^{i}}}{Y_{b}^{i} \prod_{l \in\{C, D\}}\left(P_{l, c}^{i}\right)^{\gamma_{l}^{i}}}-1\right) \times 100
$$

Finally, as emissions are proportional to energy use, the counterfactual percentage change in a country's level of carbon emissions is equal to the percentage change in energy use and hence given by

$$
\Delta E^{i} \equiv\left[\frac{E_{c}^{i}}{E_{b}^{i}}-1\right] \times 100=\left[\frac{e_{b}^{i} \sum_{l \in\{C, D\}} \alpha_{l}^{i} Y_{l, c}^{i}}{e_{c}^{i} \sum_{l \in\{C, D\}} \alpha_{l}^{i} Y_{l, b}^{i}}-1\right] \times 100
$$

using $E^{i}=\sum_{l \in\{C, D\}} \alpha_{l}^{i} Y_{l}^{i} / e^{i}$, which follows from factor market clearing. 


\subsection{Decomposing the Emission Effect}

Starting from $E^{i}=\sum_{l \in\{C, D\}} \alpha_{l}^{i} Y_{l}^{i} / e^{i}$, a country's carbon emissions can be reexpressed as follows:

$$
E^{i}=\left(1 / e^{i}\right)\left(\alpha_{C}^{i}\left(1-\kappa^{i}\right)+\alpha_{D}^{i} \kappa^{i}\right) \tilde{Y}^{i}
$$

where $\tilde{Y}^{i} \equiv \sum_{l \in\{C, D\}} Y_{l}^{i}$ is total GDP without tariff revenues and $\kappa \equiv Y_{D}^{i} / \tilde{Y}^{i}$ denotes the dirty production share. Following Copeland and Taylor (1994), taking the total differential yields the following decomposition:

$$
d E^{i}=\underbrace{\frac{\partial E^{i}}{\partial \tilde{Y}^{i}} d \tilde{Y}^{i}}_{\text {scale effect }}+\underbrace{\frac{\partial E^{i}}{\partial \kappa^{i}} d \kappa^{i}}_{\text {composition effect }}+\underbrace{\frac{\partial E^{i}}{\partial e^{i}} d e^{i}}_{\text {technique effect }}
$$

Scale effect. The effect of a ceteris paribus increase of a country's production on its emissions is positive and proportional to the rise in production:

$$
\frac{\partial E^{i}}{\partial \tilde{Y}^{i}}=\left(1 / e^{i}\right)\left(\alpha_{C}^{i}\left(1-\kappa^{i}\right)+\alpha_{D}^{i} \kappa^{i}\right)>0 \text { and } \frac{\partial E^{i}}{\partial \tilde{Y}^{i}} \frac{\tilde{Y}^{i}}{E^{i}}=1
$$

Composition effect. The effect of an increase of the dirty production share on emissions is always positive:

$$
\frac{\partial E^{i}}{\partial \kappa^{i}}=\left(\tilde{Y}^{i} / e^{i}\right)\left(\alpha_{D}^{i}-\alpha_{C}^{i}\right)>0 \text { as } \alpha_{D}^{i}>\alpha_{C}^{i} \forall i
$$

Technique effect. The effect of an increase of the energy price on emissions is always negative:

$$
\frac{\partial E^{i}}{\partial e^{i}}=-\left(\alpha_{C}^{i}\left(1-\kappa^{i}\right)+\alpha_{D}^{i} \kappa^{i}\right) \tilde{Y}^{i} /\left(e^{i}\right)^{2}<0
$$

In our base model, the energy price is exogenous and we do not change it in our counterfactual scenario. Hence, there is no technique effect in our baseline results. This changes in the extended model considered in section 7 . 


\subsection{Emission Effects of Tariffs}

We are interested in the change in emissions due to changes in tariffs between all countries in all sectors. This can be approximated as follows:

$$
d E^{i}=\sum_{l \in\{C, D\}} \sum_{h=1}^{N} \sum_{k=1}^{N}\left(\frac{\partial E^{i}}{\partial \tilde{Y}^{i}} \frac{\partial \tilde{Y}^{i}}{\partial \tau_{l}^{h k}}+\frac{\partial E^{i}}{\partial \kappa^{i}} \frac{\partial \kappa^{i}}{\partial \tau_{l}^{h k}}+\frac{\partial E^{i}}{\partial e^{i}} \frac{\partial e^{i}}{\partial \tau_{l}^{h k}}\right) d \tau_{l}^{h k}
$$

Unfortunately, there are no analytical expressions for the derivatives with respect to tariffs (apart from $\partial e^{i} / \partial \tau_{l}^{i j}=0$ in the base model). This is due to the complexity of the effects of carbon tariffs in a multi-country, two-sector model taking into account all general equilibrium effects. While the effects of the scale, the composition, and the energy prices on emissions can be unambiguously characterized as shown in equations $(20)$ to $(22)$, the effect of tariffs on the scale $\left(\tilde{Y}^{i}\right)$, the composition $\left(\kappa^{i}\right)$, and the energy price $\left(e^{i}\right)$ can not be analytically derived. Even more so the aggregate world effects are theoretically ambiguous, as additionally national effects can differ in sign between countries.

Nevertheless, the effects can be calculated and quantified. Specifically, the world emission effect $(W E)$ of the introduction of carbon tariffs decomposes into a world scale effect (WSE), a world composition effect (WCE), and a world technique effect (WTE), which we calculate as follows:

$$
W E \equiv \sum_{i=1}^{N} d E^{i}=W S E+W C E+W T E
$$

with

$$
\begin{gathered}
W S E \equiv \sum_{i=1}^{N} \sum_{l \in\{C, D\}} \sum_{h=1}^{N} \sum_{k=1}^{N}\left(1 / e^{i}\right)\left(\alpha_{C}^{i}\left(1-\kappa^{i}\right)+\alpha_{D}^{i} \kappa^{i}\right) \frac{\partial \tilde{Y}^{i}}{\partial \tau_{l}^{h k}} d \tau_{l}^{h k} \\
W C E \equiv \sum_{i=1}^{N} \sum_{l \in\{C, D\}} \sum_{h=1}^{N} \sum_{k=1}^{N}\left(\tilde{Y}^{i} / e^{i}\right)\left(\alpha_{D}^{i}-\alpha_{C}^{i}\right) \frac{\partial \kappa^{i}}{\partial \tau_{l}^{h k}} d \tau_{l}^{h k}
\end{gathered}
$$


$W T E \equiv \sum_{i=1}^{N} \sum_{l \in\{C, D\}} \sum_{h=1}^{N} \sum_{k=1}^{N}-\left(\alpha_{C}^{i}\left(1-\kappa^{i}\right)+\alpha_{D}^{i} \kappa^{i}\right) \tilde{Y}^{i} /\left(e^{i}\right)^{2} \frac{\partial e^{i}}{\partial \tau_{l}^{h k}} d \tau_{l}^{h k}$

\section{Estimation Method}

\subsection{Derivation of a Stochastic Model}

The aim of this section is to derive from the model developed in Section 3 an estimable stochastic version. First, note that trade costs $T_{l}^{i j}$ are not observable and therefore have to be approximated. The standard procedure is to approximate them as an exponential function of $K$ observable variables $\mathbf{z}^{i j}=\left(z_{1}^{i j}, z_{2}^{i j}, \ldots, z_{K}^{i j}\right)^{\prime}: T_{l}^{i j}=\exp \left(\left(\mathbf{z}_{l}^{i j}\right)^{\prime} \mathbf{b}_{l}\right)$, where $\mathbf{b}_{l}$ is a $(K \times 1)$ parameter vector. Adding a stochastic expression to equation (6) yields:

$$
X_{l}^{i j}=\frac{\gamma_{l}^{j} Y^{j} Y_{l}^{i}}{Y^{W}}\left(\frac{T_{l}^{i j}}{\Pi_{l}^{i} P_{l}^{j}}\right)^{1-\sigma_{l}}\left(\tau_{l}^{i j}\right)^{-\sigma_{l}} u_{l}^{i j}
$$

where $u_{l}^{i j}$ is a random error which is mean independent of all right-hand side variables with conditional expectation equal to 1.8 Pooling all exporter- or importer-specific parts of this equation, defining

$$
\mu_{l}^{i} \equiv Y_{l}^{i}\left(\Pi_{l}^{i}\right)^{\sigma_{l}-1} \quad \text { and } \quad m_{l}^{j} \equiv \gamma_{l}^{j} Y^{j}\left(P_{l}^{j}\right)^{\sigma_{l}-1}
$$

and using equation $T_{l}^{i j}=\exp \left(\left(\mathbf{z}_{l}^{i j}\right)^{\prime} \mathbf{b}_{l}\right)$, the following, more compact stochastic expression for the value of exports is obtained:

$$
X_{l}^{i j}=\frac{1}{Y^{W}} \exp \left(\left(\mathbf{z}_{l}^{i j}\right)^{\prime} \boldsymbol{\beta}_{l}\right)\left(\tau_{l}^{i j}\right)^{-\sigma_{l}} \mu_{l}^{i} m_{l}^{j} u_{l}^{i j}
$$

where $\boldsymbol{\beta}_{l}=\mathbf{b}_{l}\left(1-\sigma_{l}\right)$. We treat tariffs as zero in the benchmark case, in which $T_{l}^{i j}$ is estimated. To keep things simple in the following explanations, we sac-

${ }^{8}$ We follow the trade literature and add the error term already when describing our trade flow equation. From an econometric point of view, one might focus on deriving the expression for the conditional expectation of trade flows and add the error term later as the difference between the conditional expectation of trade flows and actual trade flows. 
rifice some generality by permanently assuming zero tariffs for the estimation (i.e. $\tau_{l}^{i j}=1$ ).

\subsection{Estimators}

Equation (30) represents a multiplicative constant-elasticity model. It has long been common practice to simply take logarithms and estimate the resulting linear model with Ordinary Least Squares (OLS), where $\mu_{l}^{i}$ and $m_{l}^{j}$ are captured by exporter and importer fixed effects. But Santos Silva and Tenreyro (2006) argue that this approach yields inconsistent parameter estimates. Further, log-linearization requires all values of $X_{l}^{i j}$ to be greater than zero. But depending on the set of countries used, there may well be a considerable number of zero entries in the trade matrix. The usual solution of simply dropping these observations is not theoretically justified and will in general lead to biased estimates.

For these reasons, we will not rely on the OLS estimator to obtain the bilateral trade costs, but rather on the Poisson Pseudo-Maximum-Likelihood (PPML) estimator suggested by Santos Silva and Tenreyro (2006). As argued by Santos Silva and Tenreyro (2006), PPML is also likely to be a more sensible choice than other consistent non-linear estimators (such as non-linear least squares or Gamma PML), because it gives equal weight to all observations. They additionally demonstrate that the PPML estimator is generally well behaved in the context of constant elasticity models by conducting Monte Carlo simulations (see Santos Silva and Tenreyro, 2011). Additionally, Fally (2014) highlights that using PPML with exporter and importer fixed effects ensures that the equilibrium constraints imposed by our model are satisfied. We therefore follow this by now standard approach and will base the empirical investigation on sector-wise PPML estimation of $(30) \mathrm{I}^{9}$ As it is common prac-

\footnotetext{
${ }^{9}$ Note that there are potential efficiency gains in employing a system estimator as in Egger, Larch, and Staub (2012), making use of the correlation of the error terms between sectors. The empirical approach in this work will be constrained to the also consistent though less efficient PPML estimator.
} 
tice, we will also estimate the model with OLS and use the resulting estimates as a robustness check.

Estimation of equation (30) with PPML gives alongside fixed effects the parameter vector estimate $\hat{\boldsymbol{\beta}}_{l}$ with corresponding variance-covariance matrix $\hat{\Omega}_{l}$. Based on this, the estimated trade costs can be obtained as

$$
\hat{T}_{l}^{i j}=\exp \left(\frac{1}{1-\sigma_{l}}\left(\left(\mathbf{z}_{l}^{i j}\right)^{\prime} \hat{\boldsymbol{\beta}}_{l}\right)\right)
$$

\subsection{Determination of Remaining Model Parameters}

We will now show how the carbon tariff for the counterfactual scenario is obtained. For the benchmark case, we will assume $\tau_{l, b}^{i j}=1$, but of course the benchmark tariff could instead be obtained from the data and the counterfactual carbon tariff then be added to the benchmark rates. Let $\lambda^{i}$ denote the implicit carbon tax in country $i$ (calculated as $i$ 's firms' energy tax expenses over $i$ 's carbon emissions). Then $\tau_{l, c}^{i j}$ can be obtained from the difference in national carbon taxes as follows:

$$
\tau_{l, c}^{i j}= \begin{cases}1+\frac{E M_{l}^{j}}{Y_{l}^{j}}\left(\lambda^{j}-\lambda^{i}\right) & \text { if } \lambda^{j}>\lambda^{i}, \\ 1 & \text { if } \lambda^{j} \leq \lambda^{i}\end{cases}
$$

where $E M_{l}^{j}$ is the amount of carbon emissions in sector $l$ and hence $E M_{l}^{j} / Y_{l}^{j}$ is the carbon intensity of production in sector $l$ in the importing country. Of course, it would generally be possible to use the carbon intensities of the exporting country instead. This would be a production-based rather than a product-based calculation of the carbon tariff rates. In our counterfactual scenario, we will follow equation (32) and hence work with product-based carbon tariffs, because they can possibly be regarded as being comparable to VAT border tax adjustments which are legitimate under WTO law (see Metcalf and Weisbach, 2009, p. 546 f.).

The expenditure share for sector $l$ in country $i, \gamma_{l}^{i}$ is calculated from the 
data as $\gamma_{l}^{i}=\mathfrak{X}_{l}^{i} / \mathfrak{X}^{i} .10$ We further follow the common approach and put $\sigma_{l}$ to a plausible value. Simplifying further by assuming a common elasticity of substitution for both sectors, we choose $\sigma_{l}=5.11$

As was mentioned in section 3, we treat energy and emissions as if there was a perfectly linear relationship. This allows us to infer the energy price of country $i$ as $e^{i}=E C^{i} / E M^{i}$, where $E C^{i}$ are total energy costs of all firms in country $i$ and $E M^{i}$ are total emissions in country $i{ }^{12}$ Treating energy and emissions as perfectly correlated further makes it possible to estimate the last missing model parameter, the cost share of emissions in country $i, \alpha_{l}^{i}$, as $\alpha_{l}^{i}=E M_{l}^{i} e^{i} / T C_{l}^{i}$, where $E M_{l}^{i}$ are the emissions in sector $l$ in country $i$ and $T C_{l}^{i}$ are the total costs of firms in the corresponding sector.

\section{Data}

\section{$5.1 \quad$ Data Sources}

For most of the data in this work, we use the Global Trade Analysis Project (GTAP) 8 database (see Narayanan, Aguiar, and McDougall, 2010). This database comprises data for 129 regions covering all countries in the world. ${ }^{13}$ The data are disaggregated to 57 sectors. As stated before, we work with the data on a bisectoral level. In order to obtain the clean and dirty sector used in the model, we divided the sectoral emission data provided in GTAP for all countries by the sectoral production data. The 50 percent of the industries for which this ratio is above the median were pooled together as the dirty sector,

\footnotetext{
${ }^{10}$ For an explanation of how sectoral GDPs and expenditures are calculated from the GTAP raw data, see Appendix B.

${ }^{11}$ This is equal to the benchmark choice of Anderson and van Wincoop (2003). We additionally solve our model for $\sigma_{l}=8$ and $\sigma_{l}=10$ as a robustness check.

${ }^{12}$ Note that the energy price is given per unit of carbon emissions, rather than per a typical energy unit such as kilowatt-hour. This is unproblematic due to the linear relationship of energy and emissions.

${ }^{13}$ Most of these regions are identical with countries, but some countries are pooled together as one region. For a list of the regions please refer to Appendix B.
} 
the rest of the industries form the clean sector 14 All further data taken from the GTAP 8 database were then aggregated to this sectoral structure. These are the bilateral trade flows used for the estimation of the gravity equation, sectoral GDPs (constructed as described in Appendix B), firms' total costs, firms' expenses for energy (and the tax part thereof) and carbon emissions. The GTAP 8 data are for the year 2007. We therefore construct the whole dataset as a cross-section for this year.

Bilateral data on regional trade agreement (RTA) memberships are taken from the WTO homepage ${ }^{15}$ All geographic variables for the estimation of the gravity equation stem from the Centre d'Etudes Prospectives et d'Informations Internationales (CEPII) dataset constructed by Head, Mayer, and Ries (2010). From the CEPII dataset we use the logarithm of the weighted distance (DIST), the contiguity variable $(C O N T I G)$, two colonial variables $(C O L O N Y$, indicating if the two countries ever had a direct colonial link, and COMCOL, indicating if the two countries once had the same colonizer) and construct a variable for common language $(C O M L A N G)$ which is one if either the two countries share an official language or if one language is spoken by at least 9 percent of the population in both countries.

As both the WTO and the CEPII data are given on a country level, we aggregated them to the GTAP 8 regional level. For the distance variable, the mean distance was used for aggregation. All of the other variables are binary. For these variables, we again took the mean when aggregating the countries and then rounded these variables to zero or one.

\subsection{Descriptive Statistics}

In this subsection, we briefly describe the most important summary statistics of the data involved. Table 1 shows the descriptives statistics for all gravity

\footnotetext{
${ }^{14}$ For a list of the industries and their grouping to the two sectors see Appendix B

${ }^{15}$ The RTA data can be downloaded from Mario Larch's website at http://www.ewf.unibayreuth.de/en/research/index.html.
} 
variables. 22 percent of the countrypairs in the dataset had signed some kind

Table 1: Descriptive Statistics for Gravity Variables

\begin{tabular}{llrrrr}
\hline & Variable & Mean & S.D. & Min & Max \\
\hline WTO & & & & & \\
CEPII & RTA & 0.22 & 0.41 & 0 & 1 \\
& DIST & 7,585 & 4,346 & 132 & 19,781 \\
& CONTIG & 0.02 & 0.15 & 0 & 1 \\
& COLONY & 0.01 & 0.12 & 0 & 1 \\
& COMCOL & 0.07 & 0.26 & 0 & 1 \\
GTAP & COMLANG & 0.13 & 0.33 & 0 & 1 \\
& & & & & \\
& $X_{C}^{i j}$, million US- $\$$ & 363.04 & 2306.25 & 0.001 & 140,512 \\
& $X_{D}^{i j}$, million US- $\$$ & 545.46 & 4414.19 & 0.002 & 263,406 \\
\hline
\end{tabular}

Notes: We have information for 128 countries, leading to $128 \times 127=16,256$ observations (excluding intra-trade flows).

of common RTA in 2007. The average weighted distance between two countries is $7,585 \mathrm{~km}$, ranging from 132 to $19,781 \mathrm{~km}$. Only two percent have a common land border. One and seven percent had a direct colonial link or a common colonizer at some point in the past, respectively. 13 percent share a common language. Average trade flows in the clean and dirty sector were 363 and 545 million US-\$, respectively.

Table 2 shows descriptive statistics for all model variables and parameters. Total production in one country varies between 1.3 billion and 14.1 trillion US$\$$, with the much larger share stemming from the clean sector. This discrepancy in the size of the two sectors also shows up in the expenditure shares, as on average 78.5 percent of national income are spent on goods from the clean sector and only 21.5 percent on goods from the dirty sector. Despite being by far smaller, the dirty sector accounts for the majority of carbon emissions (on average 163 out of the 178 million tons of $\mathrm{CO}_{2}$, which are the average total

\footnotetext{
${ }^{16}$ Note that some trade flows in both sectors are very small, but none are actually zero in the dataset used. One of the problems of OLS in estimating the gravity equation is therefore not of importance here. But this does not change the rest of the argumentation brought forward in section 4 and hence leaves PPML as the preferred estimator untouched.
} 
Table 2: Model Variables and Parameters

\begin{tabular}{|c|c|c|c|c|c|c|}
\hline & Variable & Obs & Mean & S.D. & Min & Max \\
\hline \multicolumn{7}{|l|}{ Production } \\
\hline \multirow[t]{3}{*}{ (billion US-\$) } & $Y^{i}$ & 128 & 436 & 1406 & 1.3 & 14,062 \\
\hline & $Y_{C}^{i}$ & 128 & 376 & 1312 & 0.9 & 13,241 \\
\hline & $Y_{D}^{i}$ & 128 & 60 & 110 & 0.2 & 820 \\
\hline \multicolumn{7}{|l|}{ Emissions } \\
\hline \multirow[t]{3}{*}{$\left(\mathrm{mT}\right.$ of $\left.\mathrm{CO}_{2}\right)$} & $E^{i}$ & 128 & 178 & 610 & 0.3 & 4,922 \\
\hline & $E_{C}^{i}$ & 128 & 14 & 47 & 0.0 & 378 \\
\hline & $E_{D}^{i}$ & 128 & 163 & 565 & 0.3 & 4,544 \\
\hline \multirow{3}{*}{$\begin{array}{l}\text { Energy price/Carbon tax } \\
\left(\mathrm{US}-\$ / \mathrm{t} \mathrm{CO}_{2}\right)\end{array}$} & & & & & & \\
\hline & $e^{i}$ & 128 & 393 & 198 & 82 & 1,321 \\
\hline & $\lambda^{i}$ & 128 & 31 & 39 & -14 & 171 \\
\hline \multicolumn{7}{|l|}{ Energy cost share } \\
\hline & $\alpha_{C}^{i}$ & 128 & 0.013 & 0.026 & 0.000 & 0.240 \\
\hline & $\alpha_{D}^{i}$ & 128 & 0.201 & 0.098 & 0.036 & 0.541 \\
\hline \multicolumn{7}{|l|}{ Expenditure share } \\
\hline & $\gamma_{C}$ & 1 & 0.785 & 0.086 & 0.504 & 0.918 \\
\hline & $\gamma_{D}$ & 1 & 0.215 & 0.086 & 0.082 & 0.496 \\
\hline \multicolumn{7}{|l|}{ Carbon tariffs } \\
\hline & $\tau_{C, c}^{i j}-1$ & 16,256 & 0.0006 & 0.001 & 0 & 0.036 \\
\hline & $\tau_{D, c}^{i j}-1$ & 16,256 & 0.0265 & 0.045 & 0 & 0.995 \\
\hline \multicolumn{7}{|l|}{ Trade costs } \\
\hline & $\left(t_{C}^{i j}\right)^{1-\sigma}$ & 16,256 & 0.0037 & 0.004 & 0.0011 & 0.068 \\
\hline & $\left(t_{D}^{i j}\right)^{1-\sigma}$ & 16,256 & 0.0009 & 0.001 & 0.0002 & 0.031 \\
\hline \multicolumn{7}{|l|}{ Elasticity of substitution } \\
\hline & $\sigma$ & 1 & 5 & - & - & \\
\hline
\end{tabular}

Notes: All values in this table except the trade costs and the elasticity of substitution are either taken directly or calculated from the GTAP 8 data. The values of $t_{l}^{i j}$ are obtained by estimating the gravity equation and $\sigma$ is simply put to 5 . 
emissions). Countries' total carbon emissions range between almost none and close to 5 billion tons. Energy prices also show huge variation, from 82 US- $\$$ per ton of $\mathrm{CO}_{2}$ up to $1,321 \mathrm{US}-\$ /$ ton of $\mathrm{CO}_{2}$. The tax component of this price (i.e. the implicit carbon tax) is even negative in a few cases, implying that some countries subsidize the use of energy. Implicit carbon taxes therefore range from -14 to 171 US- $\$$ per ton of $\mathrm{CO}_{2}$. The average cost share of carbon emissions is 1.3 percent in the clean sector and 20.1 percent in the dirty sector. Accordingly, carbon tariffs in the clean sector are very low: 0.06 percent on average, ranging from zero to 3.6 percent. Average carbon tariffs in the dirty sector are 2.65 percent ranging from zero to a few outliers as high as 99.5 percent. As stated before, the elasticity of substitution is put to five.

\section{Results}

\subsection{Regression Results}

As was described in section 4, the gravity equation resulting from the model developed in section 3 is estimated both with OLS and PPML. The corresponding results are given in table 3. The results are in line with the usual findings. Almost all variables included are highly significant for both sectors in all specifications. The exceptions are the two colonial variables in the PPML estimate for the clean sector and the language variable in the PPML estimate for the dirty sector. Even though these three coefficients lack significance, they still show the expected sign. Estimation with OLS and PPML yield very similar results. This might be due to the fact that we estimate the gravity equation for the clean and dirty sector separately, which potentially reduces the heterogeneity of trade flows making OLS more reasonable, though still inconsistent. Only for the contiguity variable, OLS yields much higher estimates (surprisingly high in fact). As the calculation of the trade costs is based on the consistent PPML estimates, we will focus on these values in the following 
Table 3: Estimation Results for the Gravity Equation

\begin{tabular}{lllll}
\hline Dep. Var. & $X_{C}^{i j}$ & $\begin{array}{l}\ln X_{C}^{i j} \\
(1)\end{array}$ & $\begin{array}{l}X_{D}^{i j} \\
(2)\end{array}$ & $\begin{array}{l}\ln X_{D}^{i j} \\
(4)\end{array}$ \\
& PPML & OLS & PPML & OLS \\
\hline & & & & \\
RTA & $0.286^{* * *}$ & $0.251^{* * *}$ & $0.217^{* * *}$ & $0.192^{* * *}$ \\
& $(0.056)$ & $(0.023)$ & $(0.073)$ & $(0.030)$ \\
DIST & $-0.685^{* * *}$ & $-0.711^{* * *}$ & $-0.872^{* * *}$ & $-0.866^{* * *}$ \\
& $(0.032)$ & $(0.017)$ & $(0.039)$ & $(0.021)$ \\
CONTIG & $0.308^{* * *}$ & $1.014^{* * *}$ & $0.352^{* * *}$ & $1.228^{* * *}$ \\
COLONY & $(0.064)$ & $(0.085)$ & $(0.068)$ & $(0.095)$ \\
& 0.054 & $0.512^{* * *}$ & $0.236^{* * *}$ & $0.559^{* * *}$ \\
COMCOL & $(0.088)$ & $(0.074)$ & $(0.091)$ & $(0.080)$ \\
COMLANG & 0.095 & $0.317^{* * *}$ & $0.439^{* * *}$ & $0.555^{* * *}$ \\
& $(0.111)$ & $(0.040)$ & $(0.163)$ & $(0.052)$ \\
CONST & $0.200^{* * *}$ & $0.288^{* * *}$ & 0.111 & $0.245^{* * *}$ \\
& $(0.073)$ & $(0.028)$ & $(0.070)$ & $(0.037)$ \\
& $13.343^{* * *}$ & $13.312^{* * *}$ & $15.866^{* * *}$ & $14.748^{* * *}$ \\
(Pseudo-) $R^{2}$ & $(0.367)$ & $(0.182)$ & $(0.473)$ & $(0.243)$ \\
\hline
\end{tabular}

Notes: All regressions include importer and exporter fixed effects, the coefficients of which are not shown. We have 128 countries and 16,256 bilateral observations. Robust standard errors are given in parentheses. $*$, ** and $* * *$ denote statistical significance at the 10,5 and 1 percent level, respectively.

short description of the results.

The regressions explain a very large part of the variation of bilateral trade flows (95.8 percent for the clean and 89.4 percent for the dirty sector). Ignoring general equilibrium effects for the moment, an impression of the coefficients can be given by the implied percentage changes. RTAs lead to a $(\exp (0.286)-$ 1) $\times 100=33.1$ percent increase in trade flows in the clean sector and to a 24.2 percent increase in the dirty sector. Ignoring general equilibrium effects, distance is found to reduce trade flows a little less in the clean than in the dirty sector. A one percent increase in distance leads to a 0.685 and a 0.872 percent reduction, respectively. All further geographical, political and cultural variables included from the CEPII dataset increase bilateral trade flows, with effects varying from 5.5 percent for having a direct colonial link in the clean 
sector $((\exp (0.054)-1) \times 100)$ to 55.1 percent for sharing a common colonizer in the dirty sector $((\exp (0.439)-1) \times 100)$.

\subsection{Counterfactual Scenario}

As was stated above, structural gravity models allow the investigation of counterfactual scenarios, taking into account general equilibrium effects. The model developed in section 3 can be used to conduct scenarios for exogenous changes in trade costs, energy/carbon prices or carbon tariffs. We analyze the latter case.

The carbon tariff rates are obtained as described in section 4.3. Then the model is solved for the scaled equilibrium prices, sectoral productions and total national income (putting scaled equilibrium prices in Albania to one, thereby implicitly using the wage in Albania as the numeraire) and the percentage changes in trade flows, real income and carbon emissions are calculated. In this section, we will (mostly graphically) present the results for the latter three variables. Additionally, in Appendix C, the exact numerical results are given as well as numerical and graphical representations of the percentage changes in sectoral productions.

To obtain information about the precision of our results of the counterfactuals, we bootstrap 500 times from our parameter estimates reported in columns (1) and (3) of table 3 along with the corresponding variance-covariance matrix obtained in the estimation, i.e. we draw 500 pairs of vectors from the two sector-specific $K$-dimensional multivariate normal distributions $\mathcal{N}_{K}\left(\hat{\boldsymbol{\beta}}_{l}, \hat{\boldsymbol{\Omega}}_{l}\right)$. We then solve the model in the benchmark case and the counterfactual for each of the 500 bootstraps. We report the obtained standard errors in paranthesis below the corresponding point estimates in table 4 in Appendix C. All confidence intervals reported for counterfactual values are also obtained using this bootstrapping procedure.

The way in which the carbon tariffs are calculated implies that for each country pair the country with the higher implicit carbon tax imposes a tariff 


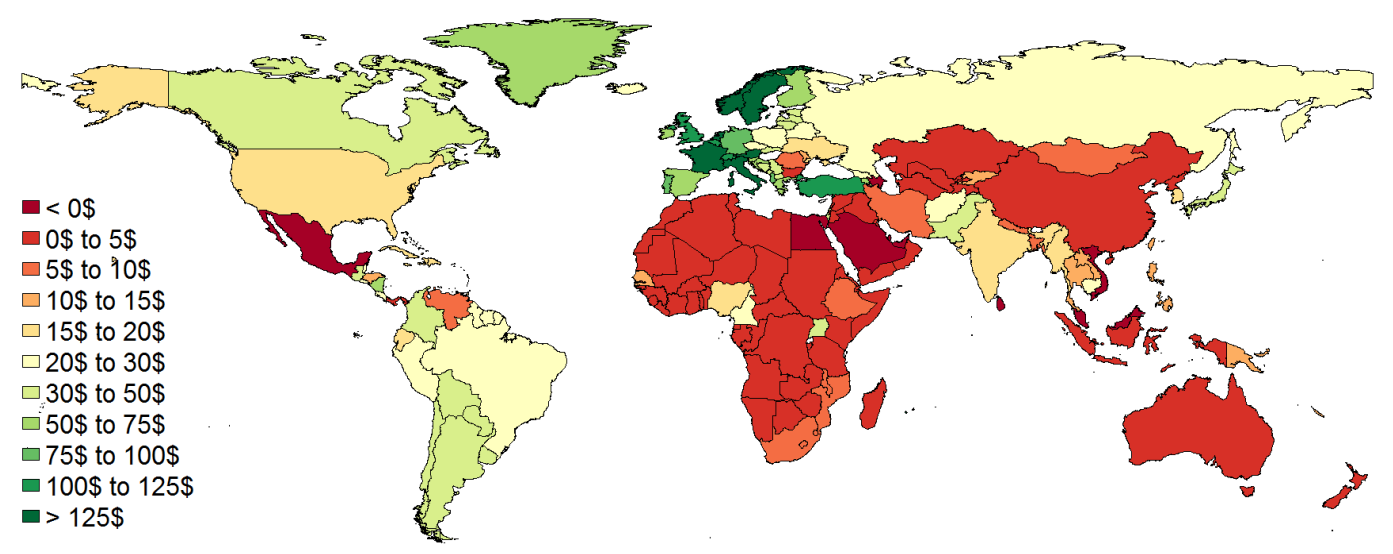

Notes: This figure shows national implicit carbon taxes $\left(\lambda^{i}\right)$ around the world. The values range between -14 US- $\$$ in Malaysia and 171 US- $\$$ in Sweden. Red represents low carbon taxes, while green represents high values of $\lambda^{i}$. Values below zero are due to implicit carbon subsidies in a few Arabic and Asian countries.

on imported goods from the other country. In order to give an overview which countries are imposing tariffs in most cases and which countries more often have to pay them, figure 1 presents the national implicit carbon taxes in all 128 countries.17 The larger the difference between two countries' carbon taxes, the higher is the carbon tariff imposed by the high-price country. Additionally, due to the higher carbon intensity in the dirty sector, the percentage carbon tariffs in the dirty sector are obviously higher than in the clean sector. The implicit national carbon taxes $\left(\lambda^{i}\right)$ vary between -14 US-\$ in Malaysia (i.e. an implicit carbon subsidy) and 171 US-\$ in Sweden. Generally, carbon taxes tend to be very high in European countries and very low for large parts of Africa, Asia and Oceania. It follows that European countries most often impose tariffs, while African, Asian and Oceanic countries in many cases have to pay tariffs. Further, many North and South American countries have to pay tariffs when exporting to Europe and impose tariffs in most other cases.

Figures 2 to 4 show the most important results of the counterfactual in-

\footnotetext{
${ }^{17}$ For the exact values of the carbon prices, see table 4 in Appendix $\mathrm{C}$
} 


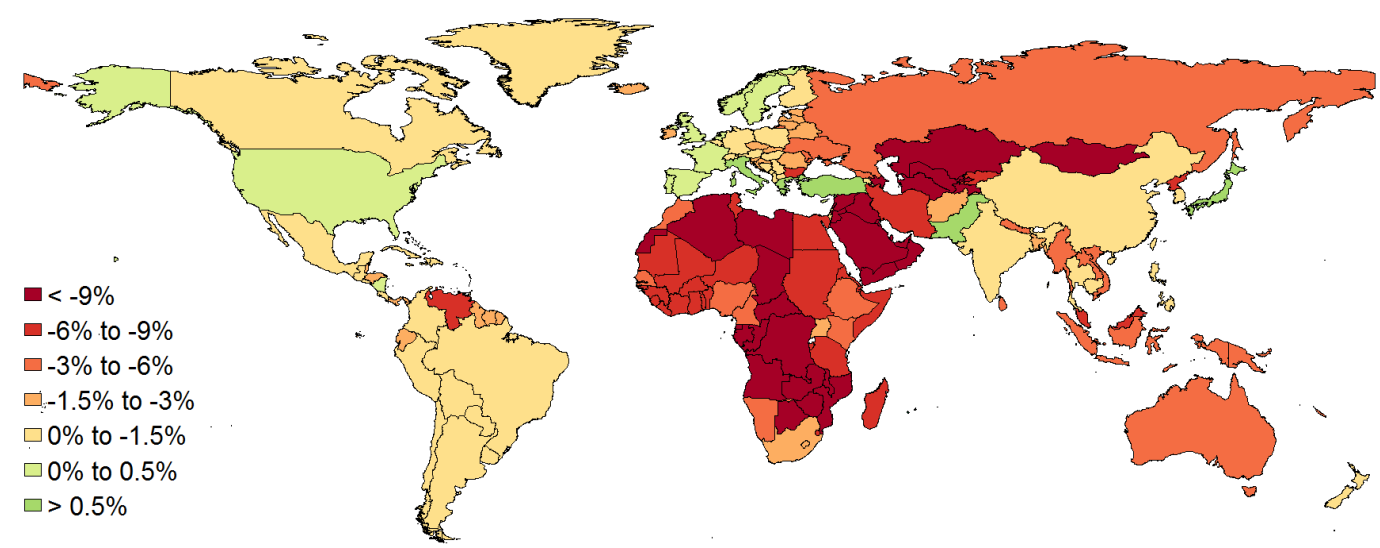

Notes: This figure shows the percentage changes in trade flows due to the counterfactual introduction of carbon tariffs. Green represents an increase in a country's trade, while red represents a reduction. The values range between -17.9 percent for Azerbaijan and 1.0 percent for Greece. The corresponding change in world trade flows is a 0.49 percent decrease.

troduction of carbon tariffs. As carbon tariffs are a (climate-policy related) trade-policy instrument, a plausible starting point for the evaluation of its effects is to look at the changes in trade flows. These are given in figure 2. It is apparent that trade flows are reduced for most countries, but there are considerable differences in the effects for different countries. The percentage changes vary between a 17.9 percent reduction for Azerbaijan and a 1.0 percent increase for Greece. Comparing the figure with the representation of the carbon taxes given by figure 1, one can state a distinct relation between a country's carbon tax and the trade effects of carbon tariffs: those countries with low carbon taxes (which hence have to pay most and highest carbon tariffs) undergo the strongest negative effects in the counterfactual scenario. While most European countries (except a few Eastern European ones with low carbon taxes) actually experience a slight increase in their trade flows and most American countries face moderate (positive or negative) effects, many African and Asian countries with very low carbon taxes are subject to a comparatively strong reduction of their trade flows. Overall, aggregate world trade flows decrease by only 0.5 percent. This is explained by the high trade shares of many European coun- 
Figure 3: Percentage Changes in Real Income

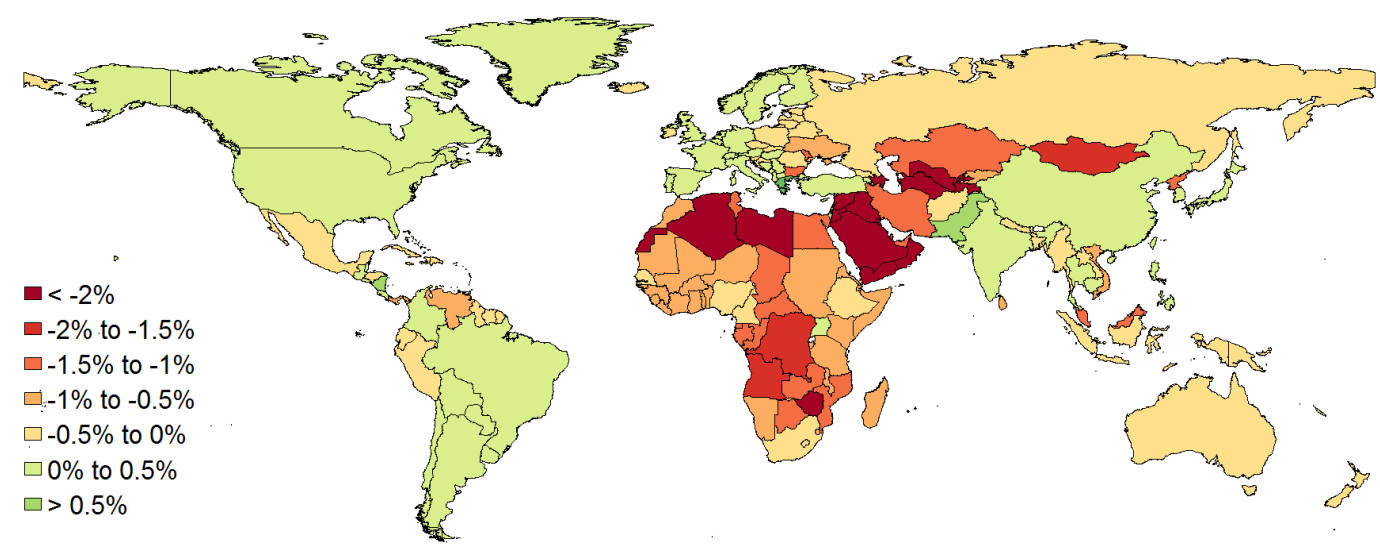

Notes: This figure shows the percentage changes in real income due to the counterfactual introduction of carbon tariffs. Green represents an increase in a country's real income, while red represents a reduction. The values range between -3.8 percent for Azerbaijan and 0.8 percent for Greece.

Figure 4: Percentage Changes in Carbon Emissions

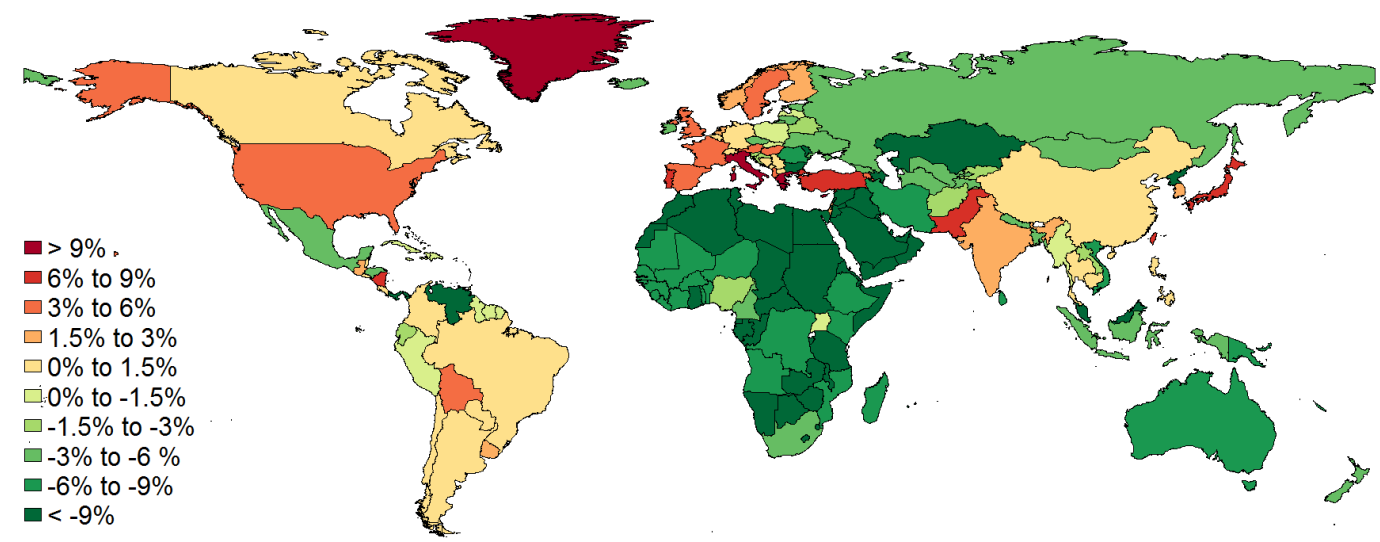

Notes: This figure shows the percentage changes in carbon emissions due to the counterfactual introduction of carbon tariffs. Red represents an increase in a country's emission level, while green represents a reduction. The values range between -14.6 percent for Bahrain and 12.9 percent for Greece. The corresponding change in world carbon emissions is a 0.83 percent decrease. 
tries which tend to have stable or slightly higher trade flows after introduction of the tariff.

Figure 3 shows the percentage changes in real income. First of all, welfare effects in terms of real income are negative for the majority of countries (65 percent), the largest being a -3.8 percent effect for Azerbaijan. While there are also countries with positive effects, these welfare gains are comparatively small (the largest being a 0.8 percent increase for Greece). Overall, the relative picture of the different effects for different countries given by figure 3 is strongly linked to the respective image obtained for the trade flows: those countries which experience strong reductions in trade flows also tend to experience strong welfare losses. As most of these countries are developing countries in Africa and Asia, the counterfactual scenario would mostly decrease the welfare of already relatively poor countries.

Figure 4 shows the percentage changes of carbon emissions around the world. The introduction of carbon tariffs leads to significant changes in national carbon emissions. "Clean" industrialized countries with comparatively high carbon taxes (mainly in Europe and North America) experience an increase in their carbon emissions. In contrast, most of the "dirtier" developing countries (in Africa and parts of Asia) strongly reduce their emissions after the tariff introduction. The values range between -14.6 percent for Bahrain and 12.9 percent for Greece. The corresponding change in world carbon emissions is a 0.83 percent decrease, with a bootstrapped $95 \%$ confidence interval of $[-0.92,-0.80]$.

Comparing figure 4 to figure 1, one can see that emissions are massively shifted from countries with low carbon taxes to countries with high carbon taxes. If we see carbon tax differences as a cause for carbon leakage, carbon tariffs strongly reduce this effect.

The pattern in figure 4 is mainly driven by the composition effect. On average, it accounts for 73 percent of the change in national carbon emissions. It ranges from -10.4 to 11.6 percent and is negative for 63 percent of the coun- 
tries. The scale effect is less strong (between -5.1 and 1.2 percent), negative for most countries (79 percent) and positively correlated with the composition effect. The latter implies that countries that experience lower emissions due to a shift of production towards the clean sector at the same time also reduce more strongly their overall production, which further lowers their emissions.

The relative importance of the scale and composition effect is different on the aggregate level. About two thirds of the world emission reduction are due to the world scale effect (-0.58 percent with bootstrapped $95 \%$ confidence interval $[-0.63,-0.55])$, and only one third is explained by the world composition effect $(-0.28$ percent with bootstrapped $95 \%$ confidence interval $[-0.40,-0.20])$. This is because positive and negative national composition effects tend to cancel each other out, while national scale effects are negative for most countries, leading accordingly to a clearly negative aggregate effect.

To further highlight the relationship between carbon tariffs and the change in carbon emission, we calculate a sectoral-import share weighted average carbon tariff per country as follows:

$$
\bar{\tau}^{i} \equiv \sum_{l \in\{C, D\}} \sum_{j=1}^{N} \frac{X_{l, b}^{j i}}{\sum_{k \neq i} X_{l, b}^{k i}} \tau_{l, c}^{j i} .
$$

Figure 5 shows a clear positive relationship between the average tariff and the change in carbon emissions, i.e., countries with a higher carbon tariff on their imports see a shift in their economy to dirty production leading to higher emissions. Figures 6 and 7 decompose again into scale and composition effect. The main messages from these figures are first that the positive relationship between the average tariff and the emission effects holds for both parts, and second that the composition effect is of comparably greater importance at the national level, as already highlighted above.

The decomposition of the emission effect turns out to also give an interesting insight concerning the welfare effects of carbon tariffs. As can be seen in figure 8 , there is a very close relationship between a country's scale effect and 
Figure 5: Scatter plot of $\Delta E^{i}$ vs. $\bar{\tau}^{i}$

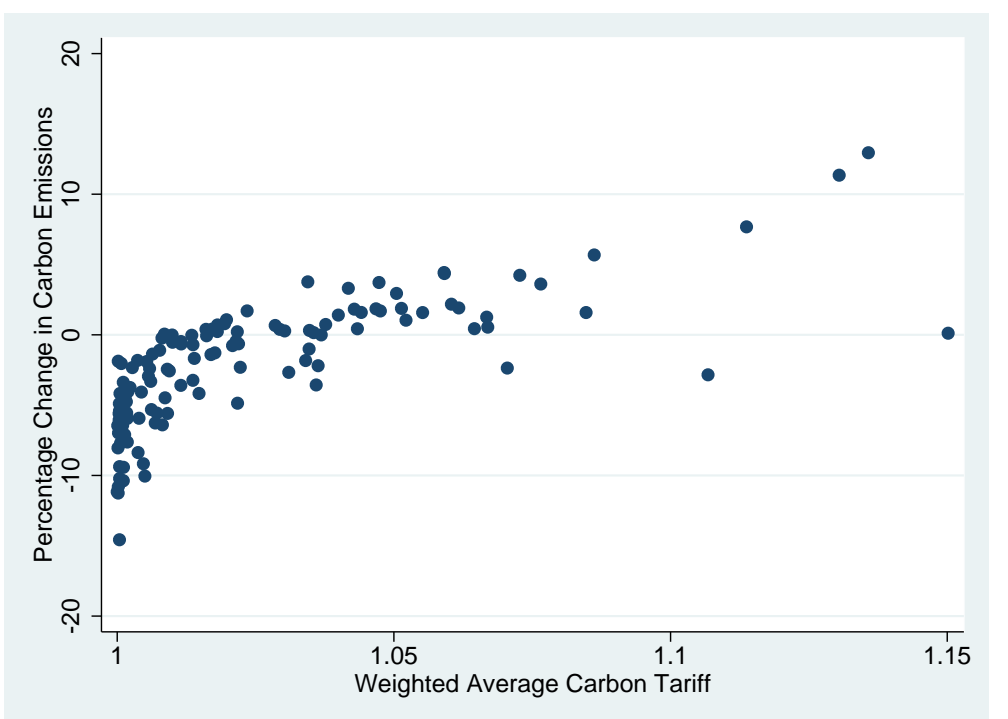

Figure 6: Scatter plot of $\left(\partial E^{i} / \partial \tilde{Y}^{i}\right) d \tilde{Y}^{i} / E_{b}^{i}$ vs. $\bar{\tau}^{i}$

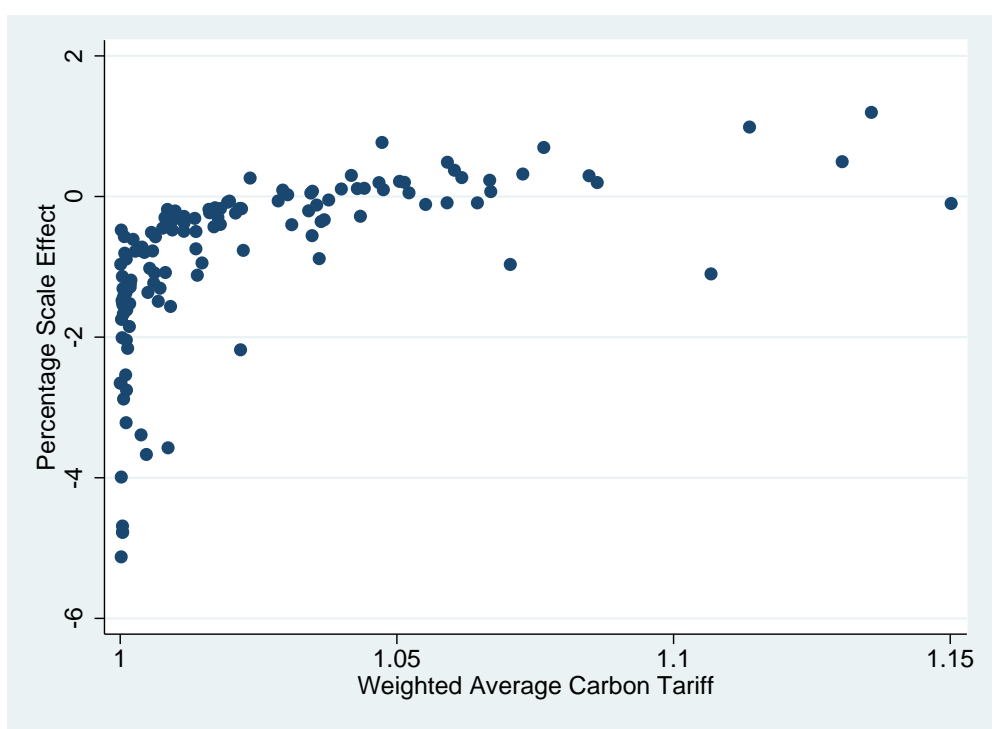


Figure 7: Scatter $\operatorname{plot}\left(\partial E^{i} / \partial \kappa^{i}\right) d \kappa^{i} / E_{b}^{i}$ vs. $\bar{\tau}^{i}$

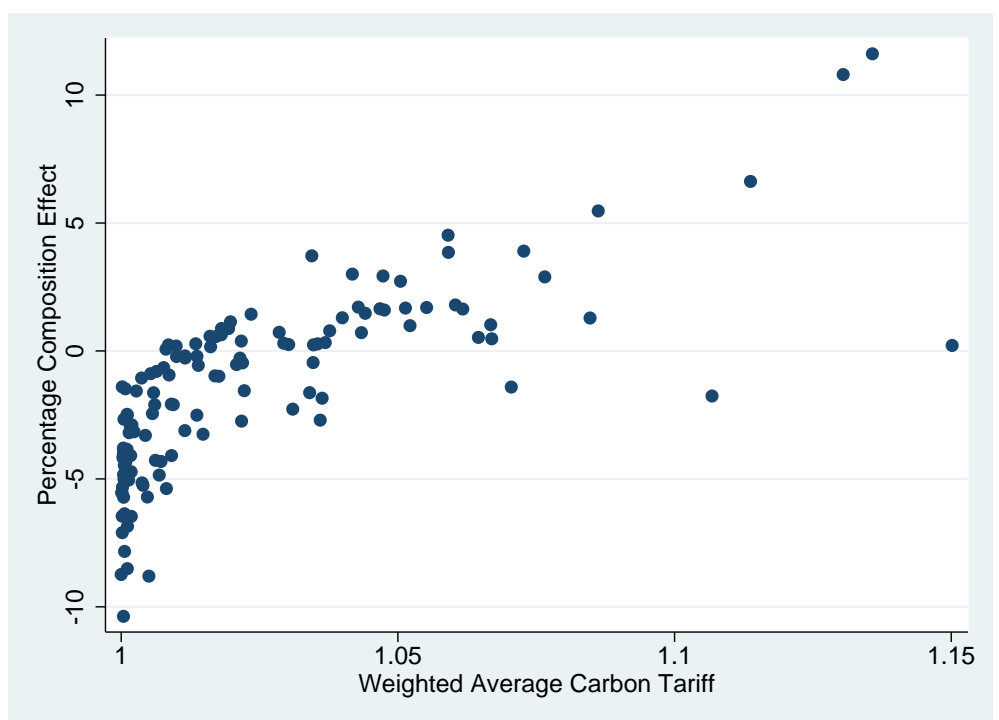

its change in real income (the correlation is 0.97). Hence, looking at the world emission reduction, the reduction due to changes in composition appears to be "welfare neutral", while the welfare costs of carbon tariffs stem from the overall reduction in scale.

Before extending our model to incorporate energy production, we discuss the robustness of our results with respect to the elasticity of substitution $\sigma_{l}$, the only parameter we did not directly obtain from our data. In our benchmark results we set $\sigma_{C}=\sigma_{D}=5$. We now investigate the cases where $\sigma_{C}=\sigma_{D}=8$ and $\sigma_{C}=\sigma_{D}=10$, respectively. For the sake of brevity, we restrict the discussion to the changes in world carbon emissions. Details for trade flows, welfare and carbon emissions at the country level are available upon request. The main findings on world carbon emissions turn out to be very robust. In fact, a higher elasticity of substitution leads to a slightly larger decrease of world carbon emissions. For $\sigma_{l}=8$ we find a decrease of 0.855 percent (with bootstrapped $95 \%$ confidence interval $[-0.97,-0.80]$ ), and for $\sigma_{l}=10$ the decrease amounts to 0.860 percent (with bootstrapped $95 \%$ confidence interval $[-0.99,-0.80])$. The reason for the stronger decrease is that higher $\sigma_{l}$ 's lead to 
Figure 8: Scatter plot of $\Delta R^{i}$ vs. $\left(\partial E^{i} / \partial \tilde{Y}^{i}\right) d \tilde{Y}^{i} / E_{b}^{i}$

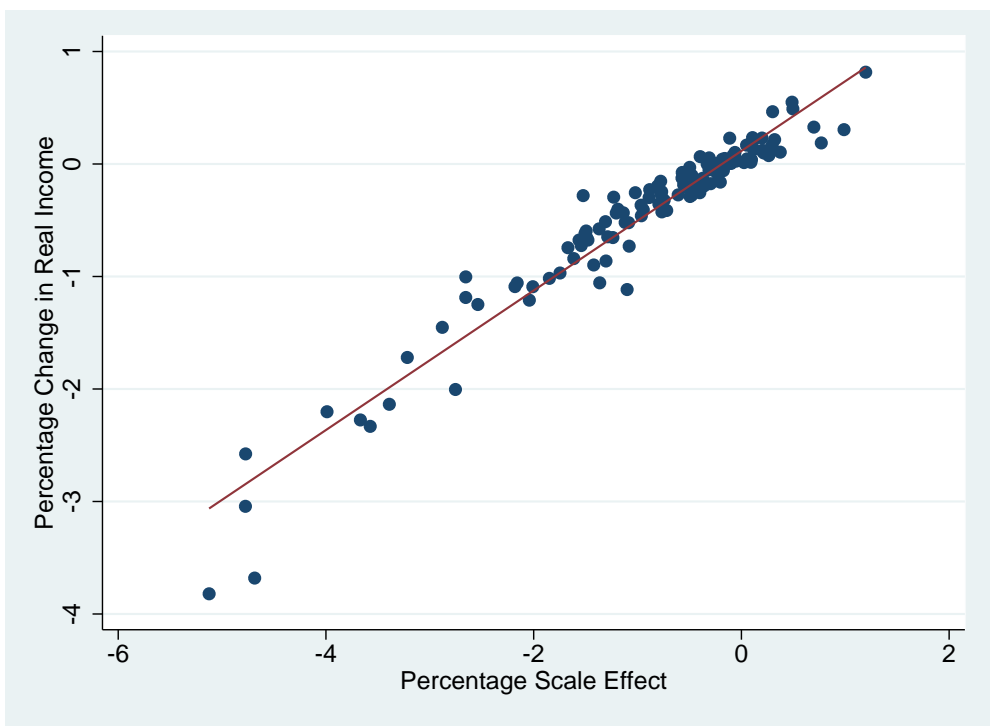

a higher responsiveness of trade flows with respect to carbon tariffs. Hence, the production reallocation between low carbon tax countries and high carbon tax countries becomes stronger. This increases the effect driving down world carbon emissions. Also the result that the scale effect accounts for about two thirds of the emission effect in the aggregate holds up.

\section{Extension: Incorporating Energy Production}

The model developed in section 3 did not allow for energy-market leakage effects. But the introduction of carbon tariffs influences energy demand around the world. Therefore, it would be a desirable feature for the model if the national energy prices were not exogenous but would also be influenced by the price of internationally tradable energy resources, such as oil. In this section, we explore how our results of the benchmark model change if we augment the model by an energy production function.

We extend the model by specifying a production function of the following form: $E^{i}=\sum_{l \in\{C, D\}} E_{l}^{i}=A_{E}^{i}\left(L_{E}^{i}\right)^{\xi^{i}}\left(R^{i}\right)^{1-\xi^{i}}$, where $R$ is a freely internationally tradable input resource and the $E$ subscript denotes the energy sector 
which is not part of the $l$ sectors. The international character of the resource factor implies that factor income associated with production in a certain country no longer incurs only in that country. We therefore define total national income in terms of factor incomes and tariff revenues. Additionally, we have to calculate two additional parameters, a country's resource endowment share and the resource cost share in energy production, which are both based on data from the GTAP 8 database. For details on the model extension and the calculation of the two additional parameters, please refer to Appendix A.3.

We conduct the same counterfactual experiment as described in section 6.2 again in the extended framework. Again, world carbon emissions decrease. The effect is less strong, -0.30 percent (with bootstrapped 95\% confidence interval $[-0.40,-0.23])$ compared to -0.83 percent in the base model. This result is driven by the technique effect which is no longer zero in the extended model. The overall lower energy demand drives down the international resource price. This makes a more energy-intensive production worthwhile, leading to higher world emissions due to a positive world technique effect of 0.50 percent (with bootstrapped $95 \%$ confidence interval $[0.48,0.53]$ ). This partly counterbalances the negative world scale and composition effects of -0.51 percent (with bootstrapped $95 \%$ confidence interval [-0.55, -0.48]) and -0.33 percent (with bootstrapped $95 \%$ confidence interval $[-0.45,-0.25]$ ), respectively, reducing the decrease in world carbon emissions compared to the scenario with purely country-specific energy prices.

\section{Conclusions}

An effective international solution for $\mathrm{CO}_{2}$ emission reductions is not in sight. Hence we are most likely to see a mixture of national and regional efforts to reduce carbon emissions, at least in the short to medium term. But the global effectiveness of unilateral measures is undermined by carbon leakage, if carbon emissions are shifted via international trade. One policy measure that 
may tackle this problem and that is heavily discussed in this context is the introduction of carbon tariffs.

Using a multi-sector, two-factor Anderson and van Wincoop (2003)-type structural gravity model, we counterfactually introduce carbon tariffs to investigate the trade, welfare and emission effects. We find that trade decreases, welfare (in terms of real income) is reduced in most countries (and most strongly in the developing world), carbon emissions are shifted from countries with low carbon taxes to countries with high carbon taxes (i.e. carbon leakage is reduced) and world carbon emissions decrease by 0.83 percent. Hence, based on our model, we find that carbon tariffs have some desirable effects: a reduction of carbon leakage and a decrease of world emission. But these effects have welfare costs which are mainly borne by developing countries.

Our decomposition of the carbon emission changes into scale, composition and technique effects shows that at the national level the composition effect turns out to be the most important one. However, at the aggregate world level, the scale effect explains two thirds of the carbon emission effects. The reason is that from an aggregate perspective, the opposing national composition effects partly cancel each other out. When allowing for energy-market leakage in our model extension, the additional technique effect works in the opposite direction of the scale and composition effects at the aggregate level, and weakens the overall world emission change.

There are several issues in the given model framework which ask for further research. For example, there are no dynamic effects and technology is fixed (in the sense that the parameters of the production function do not change). The countries whose emissions increase due to the tariffs tend to be countries with high carbon taxes. This may very well imply that these countries are the ones which are more willing to invest in reducing their emissions. The increase they face might therefore lead to intensified efforts of these countries, while the tariffs at the same time already directly reduced emissions in countries that might otherwise not have carbon emission reduction as one of their first 
policy priorities. Nevertheless, this paper contributes to the literature by providing a framework with a sectoral structure in which counterfactual analyses of exogenous changes in trade costs, carbon taxes and carbon tariffs can be conducted.

\section{References}

Aichele, R. (2013): "Carbon Leakage with Structural Gravity," Beiträge zur Jahrestagung des Vereins für Socialpolitik 2013: Wettbewerbspolitik und Regulierung in einer globalen Wirtschaftsordnung - Session: Climate Policy I, A04-V3.

Aichele, R., and G. Felbermayr (2012): "Kyoto and the Carbon Footprint of Nations," Journal of Environmental Economics and Management, 63(3), $336-354$.

- (forthcoming): "Kyoto and Carbon Leakage: An Empirical Analysis of the Carbon Content of Bilateral Trade," Review of Economics and Statistics.

Aldy, J. E., A. J. Krupnick, R. G. Newell, I. W. Parry, and W. A. PIZER (2010): "Designing Climate Mitigation Policy," Journal of Economic Literature, 48(4), 903-934.

Anderson, J. E., And E. VAn Wincoop (2003): "Gravity with Gravitas: A Solution to the Border Puzzle," American Economic Review, 93(1), 170-192.

Anderson, J. E., And Y. Yotov (2010): "The Changing Incidence of Geography," American Economic Review, 100(5), 2157-2186.

Armington, P. S. (1969): “A Theory of Demand for Products Distinguished by Place of Production," Staff Papers - International Monetary Fund, 16(1), 159-178. 
Babiker, M. H. (2005): "Climate Change Policy, Market Structure, and Carbon Leakage," Journal of International Economics, 65(2), 421-445.

BABiker, M. H., And T. F. Rutherford (2005): "The Economic Effects of Border Measures in Subglobal Climate Agreements," Energy Journal, 26(4), 99-125.

Böhringer, C., J. C. Carbone, and T. F. Rutherford (2011): "Embodied Carbon Tariffs," NBER Working Paper No. 17376.

Böhringer, C., K. E. Rosendahl, And J. Schneider (2013): "Unilateral Climate Policy: Can OPEC Resolve the Leakage Problem?," USAEE Working Paper, 13-121.

Branstetter, L., And W. Pizer (2014): "Facing the Climate Change Challenge in a Global Economy," in Globalization in an Age of Crisis: Multilateral Economic Cooperation in the Twenty-First Century, ed. by R. C. Feenstra, and A. M. Taylor, chap. 6, pp. 215-256. University of Chicago Press, Chicago, Illinois.

Burniaux, J.-M., And J. Oliveira Martins (2012): "Carbon Leakages: A General Equilibrium View," Economic Theory, 49(2), 473-495.

Caliendo, L., and F. Parro (2015): "Estimates of the Trade and Welfare Effects of NAFTA," Review of Economic Studies, 82(1), 1-44.

Chan, H. S. R., S. Li, and F. Zhang (2013): "Firm competitiveness and the European Union emissions trading scheme," Energy Policy, 63, 1056-1064.

Copeland, B. R., And M. S. Taylor (1994): "North-South Trade and the Environment," Quarterly Journal of Economics, 109(3), 755-787. (2003): Trade and the Environment. Theory and Evidence. Princeton University Press, Princeton. 
Costinot, A., And A. Rodríguez-Clare (2014): "Trade Theory with Numbers: Quantifying the Consequences of Globalization," in Handbook of International Economics, ed. by G. Gopinath, E. Helpman, and K. Rogoff, vol. 4, chap. 4, pp. 197-261. North Holland, 4 edn.

Dekle, R., J. Eaton, and S. Kortum (2007): "Unbalanced Trade," American Economic Review, 97(2), 351-355.

(2008): "Global Rebalancing with Gravity: Measuring the Burden of Adjustment," IMF Staff Papers, 55(3), 511-540.

Eaton, J., And S. Kortum (2002): "Technology, Geography, and Trade," Econometrica, 70(5), 1741-1779.

Egger, P., M. Larch, and K. E. Staub (2012): "Trade Preferences and Bilateral Trade in Goods and Services: A Structural Approach," CEPR Working Paper No. 9051.

EgGeR, P., And S. Nigai (2012): "The Copenhagen Accord: On Required Implicit Carbon Tax Rates and Their Economic Consequences," unpublished working paper.

(forthcoming): "Energy Demand and Trade in General Equilibrium," Environmental and Resource Ecnomics.

Elliott, J., I. Foster, S. Kortum, G. Khun Jush, T. Munson, And D. Weisbach (2013): "Unilateral Carbon Taxes, Border Tax Adjusments, and Carbon Leakage," Theoretical Inquiries in Law, 14(1), 207-244.

Elliott, J., I. Foster, S. Kortum, T. Munson, F. Pérez Cervantes, And D. Weisbach (2010): "Trade and Carbon Taxes," American Economic Review: Papers and Proceedings, 100(2), 465-469.

FALly, T. (2014): "Structural Gravity and Fixed Effects," unpublished working paper. 
Felder, S., And T. F. Rutherford (1993): "Unilateral $\mathrm{CO}_{2}$ Reductions and Carbon Leakage: The Consequences of International Trade in Oil and Basic Materials," Journal of Environmental Economics and Management, $25(2), 162-176$.

Grossman, G. M., and A. B. Krueger (1993): "Environmental Impacts of a North American Free Trade Agreement," in The U.S.-Mexico free trade agreement, ed. by P. M. Garber, pp. 13-56. MIT Press, Cambridge, MA.

HEAD, K., AND T. MAYER (2014): "Gravity Equations: Workhorse, Toolkit, and Cookbook," in Handbook of International Economics, ed. by G. Gopinath, E. Helpman, and K. Rogoff, vol. 4, chap. 3, pp. 131-195. North Holland, 4 edn.

HeAd, K., T. Mayer, and J. RiEs (2010): “The Erosion of Colonial Trade Linkages after Independence," Journal of International Economics, 81(1), $1-14$.

Krugman, P. (1980): "Scale Economies, Product Differentiation, and the Pattern of Trade," American Economic Review, 70(5), 950-959.

(2009a): "Climate, Trade, Obama," URL: http://krugman.blogs.nytimes.com/2009/06/29/climate-trade-obama/.

(2009b): "Fetishizing Free Trade," URL: http://krugman.blogs.nytimes.com/2009/09/11/fetishizing-free-trade/.

McAusland, C., And N. NAJjar (forthcoming): "Carbon Footprint Taxes," Environmental and Resource Economics.

Metcalf, G. E., And D. Weisbach (2009): "The Design of a Carbon Tax," Harvard Environmental Law Review, 33(2), 499-556.

Narayanan, B., A. Aguiar, and R. McDougall (eds.) (2010): Global Trade, Assistance, and Production: The GTAP 8 Data Base. Center for Global Trade Analysis, Purdue University. 
Santos Silva, J. M. C., And S. Tenreyro (2006): "The Log of Gravity," Review of Economics and Statistics, 88(4), 641-658.

(2011): "Further Simulation Evidence on the Performance of the Poisson Pseudo-Maximum Likelihood Estimator," Economics Letters, 112(2), $220-222$.

Sinn, H.-W. (2008): "Public Policies Against Global Warming: A Supply Side Approach," International Tax and Public Finance, 15(4), 360-394.

Stiglitz, J. E., A. Sen, And J.-P. Fitoussi (2010): Mismeasuring Our Lives. The New York Press, New York.

\section{Appendix}

\section{A Detailed Model Derivations}

\section{A.1 Production Structure}

With the production structure given by equation $(9)$, the cost function can be derived as

$$
c_{l}^{i}\left(e^{i}, w^{i}, q_{l}^{i}\right)=\frac{1}{A_{l}^{i}}\left[\left(\frac{\alpha_{l}^{i}}{1-\alpha_{l}^{i}}\right)^{1-\alpha_{l}^{i}}+\left(\frac{\alpha_{l}^{i}}{1-\alpha_{l}^{i}}\right)^{-\alpha_{l}^{i}}\right]\left(e^{i}\right)^{\alpha_{l}^{i}}\left(w^{i}\right)^{1-\alpha_{l}^{i}} q_{l}^{i}
$$

Dividing by the output $q_{l}^{i}$ and rearranging gives the unit costs:

$$
\frac{c_{l}^{i}}{q_{l}^{i}}\left(e^{i}, w^{i}\right)=\frac{1}{A_{l}^{i}}\left[\left(\alpha_{l}^{i}\right)^{-\alpha_{l}^{i}}\left(1-\alpha_{l}^{i}\right)^{\alpha_{l}^{i}-1}\right]\left(e^{i}\right)^{\alpha_{l}^{i}}\left(w^{i}\right)^{1-\alpha_{l}^{i}}
$$

Under the assumption of perfect competition, the price in country $i$ equals minimal costs and, again rearranging slightly, is hence given by

$$
p_{l}^{i}=\frac{1}{A_{l}^{i}}\left(\frac{e^{i}}{\alpha_{l}^{i}}\right)^{\alpha_{l}^{i}}\left(\frac{w^{i}}{1-\alpha_{l}^{i}}\right)^{1-\alpha_{l}^{i}} .
$$


According to Shepard's lemma, the conditional demand for the input factor energy in sector $l, x_{l, E}^{i}$, is given by the partial derivative of the cost function (34):

$$
x_{l, E}^{i}\left(e^{i}, w^{i}, q_{l}^{i}\right)=\frac{\partial c\left(e^{i}, w^{i}, q_{l}^{i}\right)}{\partial e^{i}}=\frac{\alpha_{l}^{i}}{e^{i}} p_{l}^{i} q_{l}^{i}=\frac{\alpha_{l}^{i}}{e^{i}} Y_{l}^{i} .
$$

Additionally, factor market clearing ensures that the following expression holds:

$$
E^{i}=\sum_{l \in\{C, D\}} x_{l, E}^{i}
$$

$>$ From equations (37) and (38), the equilibrium amount of energy can be derived:

$$
E^{i}=\frac{\sum_{l \in\{C, D\}} \alpha_{l}^{i} Y_{l}^{i}}{e^{i}}
$$

For labor, the amount is given and the price is flexible and hence an expression for the equilibrium wage is of interest. Following the same procedure as for emissions, but solving for the factor price $w^{i}$ instead of the factor endowment $L^{i}$, yields

$$
w^{i}=\frac{\sum_{l \in\{C, D\}}\left(1-\alpha_{l}^{i}\right) Y_{l}^{i}}{L^{i}}
$$

\section{A.2 Counterfactual Change in GDP}

Using the production structure given by equation (9), inserting $E_{l}^{i}=\alpha_{l}^{i} Y_{l}^{i} / e^{i}$ into (9) and adding the counterfactual subscript, we obtain the following expression for sectoral GDP:

$$
Y_{l, c}^{i}=p_{l, c}^{i} A_{l}^{i}\left(\frac{\alpha_{l}^{i} Y_{l, c}^{i}}{e_{c}^{i}}\right)^{\alpha_{l}^{i}}\left(L_{l, c}^{i}\right)^{1-\alpha_{l}^{i}}
$$

This again represents a system of $2 N$ equations, but at the same time adds the $6 N$ unknowns $p_{l, c}^{i}, A_{l}^{i}$ and $L_{l, c}^{i}$.

In order to obtain a different expression for $L_{l, c}^{i}$, we make use of the fact that the equation for the wage given by 40 also has to hold on the sectoral 
level:

$$
w^{i}=\frac{\left(1-\alpha_{l}^{i}\right) Y_{l}^{i}}{L_{l}^{i}} .
$$

Solving for $L_{l}^{i}$ and substituting equation 40 for $w^{i}$ gives

$$
L_{l}^{i}=\frac{\left(1-\alpha_{l}^{i}\right) Y_{l}^{i} L^{i}}{\sum_{m \in\{C, D\}}\left(1-\alpha_{m}^{i}\right) Y_{m}^{i}} .
$$

Now the expression for (counterfactual) sectoral GDP can be restated as

$$
Y_{l, c}^{i}=p_{l, c}^{i} A_{l}^{i}\left(\frac{\alpha_{l}^{i} Y_{l, c}^{i}}{e_{c}^{i}}\right)^{\alpha_{l}^{i}}\left(\frac{\left(1-\alpha_{l}^{i}\right) Y_{l, c}^{i} L^{i}}{\sum_{m \in\{C, D\}}\left(1-\alpha_{m}^{i}\right) Y_{m, c}^{i}}\right)^{1-\alpha_{l}^{i}}
$$

Following Dekle, Eaton, and Kortum (2007, 2008), rewriting (44) as the counterfactual change in sectoral GDP will turn out to be of use:

$$
\frac{Y_{l, c}^{i}}{Y_{l, b}^{i}}=\left(\frac{p_{l, c}^{i}}{p_{l, b}^{i}}\right)\left(\frac{Y_{l, c}^{i} e_{b}^{i}}{Y_{l, b}^{i} e_{c}^{i}}\right)^{\alpha_{l}^{i}}\left(\frac{Y_{l, c}^{i} \sum_{m \in\{C, D\}}\left(1-\alpha_{m}^{i}\right) Y_{m, b}^{i}}{Y_{l, b}^{i} \sum_{m \in\{C, D\}}\left(1-\alpha_{m}^{i}\right) Y_{m, c}^{i}}\right)^{1-\alpha_{l}^{i}} .
$$

This equation can be restated using scaled equilibrium prices:

$$
\frac{Y_{l, c}^{i}}{Y_{l, b}^{i}}=\left(\frac{\psi_{l, c}^{i}}{\psi_{l, b}^{i}}\right)^{\frac{1}{1-\sigma_{l}}}\left(\frac{Y_{l, c}^{i} e_{b}^{i}}{Y_{l, b}^{i} e_{c}^{i}}\right)^{\alpha_{l}^{i}}\left(\frac{Y_{l, c}^{i} \sum_{m \in\{C, D\}}\left(1-\alpha_{m}^{i}\right) Y_{m, b}^{i}}{Y_{l, b}^{i} \sum_{m \in\{C, D\}}\left(1-\alpha_{m}^{i}\right) Y_{m, c}^{i}}\right)^{1-\alpha_{l}^{i}}
$$

which simplifies to equation $(13)$ in the main text.

\section{A.3 Incorporating Energy Production}

The general production function stays the same in the extended model:

$$
q_{l}^{i}=A_{l}^{i}\left(E_{l}^{i}\right)^{\alpha_{l}^{i}}\left(L_{l}^{i}\right)^{1-\alpha_{l}^{i}}
$$

As before, factor market clearing for energy holds and ensures that the following expression holds:

$$
E^{i}=\frac{\sum_{l \in\{C, D\}} \alpha_{l}^{i} Y_{l}^{i}}{e^{i}}
$$


What is new in the extended framework is a production function for energy:

$$
E^{i}=\sum_{l \in\{C, D\}} E_{l}^{i}=A_{E}^{i}\left(L_{E}^{i}\right)^{\xi^{i}}\left(R^{i}\right)^{1-\xi^{i}}
$$

where $R$ is a freely internationally tradable input resource and the $E$ subscript denotes the energy sector which is not part of the $l$ sectors. It follows from the Cobb-Douglas production structure that $1-\xi^{i}$ is the resource cost share in energy production.

The extended production structure changes the labor market clearing condition to

$$
L^{i}=L_{E}^{i}+\sum_{l \in\{C, D\}} L_{l}^{i}
$$

It also leads to a new expression for the equilibrium wage:

$$
w^{i}=\frac{\sum_{l \in\{C, D\}}\left(1-\alpha_{l}^{i}\right) Y_{l}^{i}+\xi^{i} E^{i} e^{i}}{L^{i}}=\frac{\sum_{l \in\{C, D\}}\left(1-\alpha_{l}^{i}+\xi^{i} \alpha_{l}^{i}\right) Y_{l}^{i}}{L^{i}} .
$$

We can furthermore add an international resource factor market clearing condition:

$$
\sum_{i=1}^{N} R^{i}=\overline{R^{W}}
$$

assuming the world resource endowment $\overline{R^{W}}$ and the use of it to be constant.

The expression for the energy price that is implied by the general production function 47 stays the same as in the benchmark model:

$$
e^{i}=\frac{\sum_{l \in\{C, D\}} \alpha_{l}^{i} Y_{l}^{i}}{E^{i}}
$$

$>$ From 449 , we can then derive a country's resource use as follows:

$$
R^{i}=\frac{1-\xi^{i}}{r} e^{i} E^{i}=\frac{1-\xi^{i}}{r} \sum_{l \in\{C, D\}} \alpha_{l}^{i} Y_{l}^{i}
$$

where $r$ denotes the international resource price. Summing both sides over all 
countries and solving for $r$ yields:

$$
r=\frac{1}{\overline{R^{W}}} \sum_{i=1}^{N}\left(1-\xi^{i}\right) \sum_{l \in\{C, D\}} \alpha_{l}^{i} Y_{l}^{i}
$$

The benchmark resource price $r_{b}$ can hence be calculated from the data. The international character of the resource factor implies that factor income associated with production in a certain country no longer incurs only in that country. Hence, total national income has to be newly defined in terms of factor incomes and tariff revenues:

$$
Y^{i}=L^{i} w^{i}+\omega^{i} r \overline{R^{W}}+\sum_{j=1}^{N} \sum_{l \in\{C, D\}}\left(\tau_{l}^{j i}-1\right) X_{l}^{j i}
$$

where $\omega^{i}$ is the ressource endowment share of country $i$ (and hence $\sum_{i=1}^{N} \omega^{i}=$ 1). 18

Using (51) and (55), (56) can be rewritten as

$$
Y^{i}=\sum_{l \in\{C, D\}}\left(1-\alpha_{l}^{i}+\xi^{i} \alpha_{l}^{i}\right) Y_{l}^{i}+\omega^{i} \sum_{j=1}^{N}\left(1-\xi^{j}\right) \sum_{l \in\{C, D\}} \alpha_{l}^{j} Y_{l}^{j}+\sum_{j=1}^{N} \sum_{l \in\{C, D\}}\left(\tau_{l}^{j i}-1\right) X_{l}^{j i}
$$

where

$$
X_{l}^{j i}=\frac{\psi_{l}^{j}\left(T_{l}^{j i}\right)^{1-\sigma_{l}}\left(\tau_{l}^{j i}\right)^{-\sigma_{l}}}{\sum_{k=1}^{N} \psi_{l}^{k}\left(T_{l}^{k i} \tau_{l}^{k i}\right)^{1-\sigma_{l}}} \gamma_{l}^{i} Y^{i}
$$

Using this new expression for total income, 10 can again be solved for scaled equilibrium prices in the benchmark scenario.

In the system of equations (11) to (13) that needs to be solved to conduct counterfactual analyses in the base model, (11) stays the same and 12 is substituted by (57) in the extended model. Additionally, we need a new analogue

\footnotetext{
${ }^{18}$ Note that these newly defined national incomes differ from the ones in the base model and are therefore also no longer identical to the GDPs in the data.
} 
for equation 13 . It evolves from the expression for sectoral GDP:

$$
Y_{l}^{i}=p_{l}^{i} A_{l}^{i}\left(\frac{\alpha_{l}^{i} Y_{l}^{i}}{e^{i}}\right)^{\alpha_{l}^{i}}\left(L_{l}^{i}\right)^{1-\alpha_{l}^{i}}
$$

We again need an expression for the sectoral labor force, $L_{l}^{i}$. It still has to hold that

$$
w^{i}=\frac{\left(1-\alpha_{l}^{i}\right) Y_{l}^{i}}{L_{l}^{i}} .
$$

Solving for $L_{l}^{i}$ and substituting (51) for $w^{i}$ gives

$$
L_{l}^{i}=\frac{\left(1-\alpha_{l}^{i}\right) Y_{l}^{i} L^{i}}{\sum_{l \in\{C, D\}}\left(1-\alpha_{l}^{i}+\xi^{i} \alpha_{l}^{i}\right) Y_{l}^{i}} .
$$

Using this expression and — as in the benchmark model — considering the counterfactual change in sectoral GDP yields:

$$
\left(\frac{\psi_{l, c}^{i}}{\psi_{l, b}^{i}}\right)^{\frac{1}{\sigma_{l}-1}}=\left(\frac{e_{b}^{i}}{e_{c}^{i}}\right)^{\alpha_{l}^{i}}\left(\frac{\sum_{m \in\{C, D\}}\left(1-\alpha_{m}^{i}+\xi^{i} \alpha_{m}^{i}\right) Y_{m, b}^{i}}{\sum_{m \in\{C, D\}}\left(1-\alpha_{m}^{i}+\xi^{i} \alpha_{m}^{i}\right) Y_{m, c}^{i}}\right)^{1-\alpha_{l}^{i}}
$$

Equations (11), (57), and (61) hence correspond to equations (11) to (13) in the base model. But note that they cannot yet be jointly solved because $e_{c}^{i}$ is no longer exogenous in the extended model. ${ }^{19}$ Using $(49)$, we can write the energy price as follows:

$$
e^{i}=\frac{1}{A_{E}^{i}}\left(\frac{w^{i}}{\xi^{i}}\right)^{\xi^{i}}\left(\frac{r}{1-\xi^{i}}\right)^{1-\xi^{i}}+\lambda^{i}
$$

where the first term on the right-hand side are marginal costs of energy production and $\lambda^{i}$ the country-specific unit carbon tax. For simplicity, we assume wasteful taxes, i.e., we do not account for carbon tax income in national income.

Considering the change of the energy price and additionally using (51), we

\footnotetext{
${ }^{19}$ Also, two further parameters $\left(\xi^{i}\right.$ and $\left.\omega^{i}\right)$ have to be obtained from the data, as will be described below.
} 
can obtain the following expression for the energy price in the counterfactual scenario:

$$
e_{c}^{i}=\left(\frac{\sum_{l \in\{C, D\}}\left(1-\alpha_{l}^{i}+\xi^{i} \alpha_{l}^{i}\right) Y_{l, c}^{i}}{\sum_{l \in\{C, D\}}\left(1-\alpha_{l}^{i}+\xi^{i} \alpha_{l}^{i}\right) Y_{l, b}^{i}}\right)^{\xi^{i}}\left(\frac{r_{c}}{r_{b}}\right)^{1-\xi^{i}}\left(e_{b}^{i}-\lambda^{i}\right)+\lambda^{i}
$$

We can then jointly solve equations (11), (55), (57), (61), and (63) for $Y_{c}^{i}, Y_{l, c}^{i}$, $\psi_{l, c}^{i}, r_{c}$, and $e_{c}^{i}$.

To obtain $\xi^{i}$ and $\omega^{i}$, we again use the GTAP 8 database. In order to compute the resource endowment shares, GTAP data on factor incomes can be used. Factor income is divided into five factors, one of them being natural resources. If we denote a country's factor income from natural resources by $R E^{i}$, we can simply calculate a country's resource endowment share as

$$
\omega^{i}=\frac{R E^{i}}{\overline{R^{W}}}
$$

with $\overline{R^{W}} \equiv \sum_{j=1}^{N} R E^{j}$.

The factor natural resources is only used in five of the 57 GTAP sectors. The resource cost share in energy production is calculated by first obtaining the factor cost share of natural resources for an aggregated sector comprising all sectors using the factor natural resources. Secondly, the intermediate share of this aggreagated sector in the production in three energy sectors ("Petroleum, coal products", "Electricity", and "Gas manufacture, distribution") is obtained. And finally, these two shares are multiplied for each country to give $1-\xi^{i}$, the resource cost share in energy production.

\section{B Data}

This Appendix gives some further details on the data used in this paper. First, the 128 regions and the countries which are aggregated to one region are given. Afterwards, the grouping of the sectors of the GTAP 8 database into one clean 
and one dirty sector is presented. Finally, the computation of sectoral GDPs and expenditure is displayed.

\section{B.1 Regions}

The 128 regions are: ${ }^{20}$

Albania, Argentina, Armenia, Australia, Austria, Azerbaijan, Bahrain, Bangladesh, Belarus, Belgium, Bolivia, Botswana, Brazil, Bulgaria, Cambodia, Cameroon, Canada, Caribbean (Aruba, Anguilla, Netherland Antilles, Antigua and Barbuda, Bahamas, Barbados, Cuba, Cayman Islands, Dominica, Dominican Republic, Grenada, Haiti, Jamaica, Saint Kitts and Nevis, Saint Lucia, Montserrat, Puerto Rico, Turks and Caicos Islands, Trinidad and Tobago, Saint Vincent and the Grenadines, Virgin Islands British, Virgin Islands U.S.), Central Africa (Central African Republic, Congo, Gabon, Equatorial Guinea, Sao Tome and Principe, Chad), Chile, China, Colombia, Costa Rica, Cote d'Ivoire, Croatia, Cyprus, Czech Republic, Denmark, Ecuador, Egypt, El Salvador, Estonia, Ethiopia, Finland, France, Georgia, Germany, Ghana, Greece, Guatemala, Honduras, Hong Kong, Hungary, India, Indonesia, Iran, Ireland, Israel, Italy, Japan, Kazakhstan, Kenya, Kuwait, Kyrgyzstan, Lao People's Democratic Republic, Latvia, Lithuania, Luxembourg, Madagascar, Malawi, Malaysia, Malta, Mauritius, Mexico, Mongolia, Morocco, Mozambique, Namibia, Nepal, Netherlands, New Zealand, Nicaragua, Nigeria, Norway, Oman, Pakistan, Panama, Paraguay, Peru, Phillipines, Poland, Portugal, Qatar, Rest of Central America (Belize), Rest of East Asia (Macao, Democratic People's Republic of Korea), Rest of Eastern Africa (Burundi, Comoros, Djibouti, Eritrea, Mayotte, Rwanda, Sudan, Somalia, Seychelles), Rest of Eastern Europe (Moldova), Rest of EFTA (Iceland, Lichtenstein), Rest of Europe (Andorra, Bosnia and Herzegovina,

\footnotetext{
${ }^{20}$ In parentheses, we indicate which countries are aggregated to give the respective region. The aggregated countries and regions finally used in the analysis are bold.
} 
Faroe Islands, Gibraltar, Monaco, Macedonia, San Marino, Serbia, Guernsey, Isle of Man, Jersey, Montenegro, Vatican), Rest of Former Soviet Union (Tajikistan, Turkmenistan, Uzbekistan), Rest of North Africa (Algeria, Lybia, Western Sahara), Rest of North America (Bermuda, Greenland, Saint Pierre and Miquelon), Rest of Oceania (American Samoa, Cook Islands, Fiji, Federated States of Micronesia, Guam, Kiribati, Marshall Islands, Northern Mariana Islands, New Caledonia, Niue, Nauru, Palau, Papua New Guinea, French Polynesia, Solomon Islands, Tokelau, Tonga, Tuvalu, Vanuatu, Wallis and Futuna, Samoa, Pitcairn, United States Minor Outlying Islands), Rest of South African Customs Union (Lesotho, Swaziland), Rest of South America (Falkland Islands, French Guiana, Guyana, Suriname, South Georgia and the South Sandwich Islands), Rest of Southeast Asia (Brunei Darussalam, Myanmar, Timor Leste), Rest of South Asia (Afghanistan, Bhutan, Maldives), Rest of Western Africa (Benin, Burkina Faso, Cape Verde, Guinea, Gambia, Guinea-Bissau, Liberia, Mali, Mauritania, Niger, Saint Helena, Sierra Leone, Togo), Rest of Western Asia (Iraq, Jordan, Lebanon, Palestine, Syria, Yemen), Romania, Russia, Saudi Arabia, Senegal, Singapore, Slovakia, Slovenia, South Afrcica, South Central Africa (Angola, Congo Democratic Republic)South Korea, Spain, Sri Lanka, Sweden, Switzerland, Taiwan, Tanzania, Thailand, Tunisia, Turkey, Uganda, Ukraine, United Arab Emirates, United Kingdom, United States of America, Uruguay, Vietnam, Venezuela, Zambia, Zimbabwe.

\section{B.2 Sectors}

The two sectors comprise the following GTAP 8 industries:

Clean sector: ctl (Cattle, sheep, goats, horses), oap (Animal products nec), rmk (Raw milk), cmt (Meat: cattle, sheep, goats, horse), omt (Meat products nec), vol (Vegetable oils and fats), mil (Dairy products), ofd (Food products 
nec), $b_{-}$t (Beverages and tobacco products), tex (Textiles), wap (Wearing apparel), lea (Leather products), lum (Wood products), fmp (Metal products), mvh (Motor vehicles and parts), otn (Transport equipment nec), ele (Electronic equipment), ome (Machinery and equipment nec), omf (Manufactures nec), cns (Contruction), trd (Trade), cmn (Communication), ofi (Financial Services nec), isr (Insurance), obs (Business services nec), ros (Recreation and other services), osg (PubAdmin/Defence/Health/Educat), dwe (Dwellings).

Dirty sector: pdr (Paddy rice), wht (Wheat), gro (Cereal grains nec), v_f (Vegetables, fruit, nuts), osd (Oil seeds), c_b (Sugar cane, sugar beet), pfb (Plant-based fibers), ocr (Crops nec), wol (Wool, silk-worn cocoons), frs (Forestry), fsh (Fishing), coa (Coal), oil (Oil), gas (Gas), omn (Minerals nec), pcr (Processed rice), sgr (Sugar), ppp (Paper products, publishing), p_c (Petroleum, coal products), crp (Chemical, rubber, plastic prods), nmm (Minearl products nec), i_s (Ferruous metals), nfm (Metals nec), ely (Electricity), gdt (Gas manufacture, distribution), wtr (Water), otp (Transport nec), wtp (Sea transport), atp (Air transport).

\section{B.3 Calculation of Sectoral GDPs}

In GTAP notation, $r$ refers to regions and $i$ to sectors. Then, sectoral GDP can be obtained as follows:

$$
\begin{aligned}
Y_{l}^{j}= & Y_{i}^{r} \\
= & \operatorname{VDPM}(r, i)+[(V I P A(r, i)-V I P M(r, i))+(V D P A(r, i)-V D P M(r, i))] \\
& +V D G M(r, i)+[(V I G A(r, i)-V I G M(r, i))+(V D G A(r, i)-V D G M(r, i))] \\
& +V X M D(r, i)+V S T(r, i)+(V X W D(r, i)-V X M D(r, i)) \\
& +V D F M(r, i, C G D S)+[(V I F A(r, i, C G D S)-V I F M(r, i, C G D S)) \\
& +(V D F A(r, i, C G D S)-V D F M(r, i, C G D S))] \\
& -\sum_{j} \operatorname{VIFM(r,j,i)+MTAX(r,i).}
\end{aligned}
$$




\section{B.4 Calculation of Sectoral Expenditures}

Sectoral expenditures are calculated as follows:

$$
\begin{aligned}
\mathfrak{X}_{l}^{j}= & \mathfrak{X}_{i}^{r} \\
= & V D P A(r, i)+V I P A(r, i)+V D G A(r, i)+V I G A(r, i) \\
& +V D F A(r, i, C G D S)+V I F A(r, i, C G D S) .
\end{aligned}
$$

\section{Further Results}

This appendix gives some further results for the counterfactual introduction of carbon tariffs. Additionally, the results presented graphically in section 6.2 are given in detail for all countries. Table 4 gives the implicit carbon tax $\left(\lambda^{i}\right)$, the percentage changes in trade flows $\left(\Delta X^{i}\right)$, real income $\left(\Delta R^{i}\right)$, emissions $\left(\Delta E^{i}\right)$, production in the clean sector $\left(\Delta Y_{C}^{i}\right)$, and production in the dirty sector $\left(\Delta Y_{D}^{i}\right)$, as well as the percentage scale and composition effects (PSE and PCE, respectively). Bootstrapped standard errors are given in parantheses.

\begin{tabular}{|c|c|c|c|c|c|c|c|c|}
\hline Country & $\lambda^{i}$ & $\Delta X^{i}$ & $\Delta R^{i}$ & $\Delta E^{i}$ & PSE & $\mathrm{PCE}$ & $\Delta Y_{C}^{i}$ & $\Delta Y_{D}^{i}$ \\
\hline \multirow[t]{2}{*}{ Albania } & 87.46 & -0.73 & 0.21 & 1.83 & 0.11 & 1.71 & -0.51 & 2.50 \\
\hline & & $(0.10)$ & $(0.01)$ & $(0.24)$ & $(0.01)$ & $(0.23)$ & $(0.07)$ & $(0.33)$ \\
\hline \multirow[t]{2}{*}{ Argentina } & 35.46 & -0.23 & 0.03 & 0.44 & -0.09 & 0.53 & -0.23 & 0.63 \\
\hline & & $(0.02)$ & $(0.02)$ & $(0.19)$ & $(0.04)$ & $(0.15)$ & $(0.01)$ & $(0.24)$ \\
\hline \multirow[t]{2}{*}{ Armenia } & 62.43 & -0.78 & 0.23 & 1.58 & -0.11 & 1.70 & -0.86 & 3.27 \\
\hline & & $(0.09)$ & $(0.01)$ & $(0.27)$ & $(0.01)$ & $(0.26)$ & $(0.10)$ & $(0.52)$ \\
\hline \multirow[t]{2}{*}{ Australia } & 0.63 & -2.60 & -0.28 & -5.55 & -1.52 & -4.09 & -0.68 & -5.75 \\
\hline & & $(0.18)$ & $(0.00)$ & $(0.05)$ & $(0.19)$ & $(0.23)$ & $(0.24)$ & $(0.06)$ \\
\hline \multirow[t]{2}{*}{ Austria } & 126.87 & 0.05 & 0.12 & 1.88 & 0.20 & 1.68 & -0.21 & 2.23 \\
\hline & & $(0.02)$ & $(0.03)$ & $(0.36)$ & $(0.03)$ & $(0.33)$ & $(0.05)$ & (0.43) \\
\hline \multirow[t]{2}{*}{ Azerbaijan } & -0.12 & -17.90 & -3.82 & -11.25 & -5.12 & -6.46 & 10.79 & -11.59 \\
\hline & & $(0.11)$ & $(0.09)$ & $(0.19)$ & $(0.05)$ & $(0.25)$ & $(0.68)$ & $(0.20)$ \\
\hline \multirow[t]{2}{*}{ Bahrain } & -0.10 & -11.78 & -3.68 & -14.57 & -4.69 & -10.37 & 3.61 & -14.64 \\
\hline & & $(0.20)$ & $(0.09)$ & $(0.46)$ & $(0.02)$ & $(0.49)$ & $(0.40)$ & $(0.46)$ \\
\hline
\end{tabular}

Figures 9 and 10 represent graphically the values of $\Delta Y_{C}^{i}$ and $\Delta Y_{D}^{i}$.

Table 4: Detailed Results of Counterfactual Scenario 
Table 4 - continued from previous page

\begin{tabular}{|c|c|c|c|c|c|c|c|c|}
\hline Country & $\lambda^{i}$ & $\Delta X^{i}$ & $\Delta R^{i}$ & $\Delta E^{i}$ & PSE & $\overline{\mathrm{PCE}}$ & $\Delta Y_{C}^{i}$ & $\Delta Y_{D}^{i}$ \\
\hline \multirow[t]{2}{*}{ Bangladesh } & 6.94 & -1.67 & -0.15 & -2.33 & -0.78 & -1.56 & 0.19 & -2.54 \\
\hline & & $(0.21)$ & $(0.03)$ & $(0.28)$ & $(0.03)$ & $(0.30)$ & $(0.20)$ & $(0.32)$ \\
\hline \multirow[t]{2}{*}{ Belarus } & 25.86 & -1.43 & -0.17 & -1.40 & -0.43 & -0.97 & -0.12 & -1.66 \\
\hline & & $(0.20)$ & $(0.04)$ & $(0.40)$ & $(0.03)$ & $(0.37)$ & $(0.08)$ & $(0.50)$ \\
\hline \multirow[t]{2}{*}{ Belgium } & 111.96 & -0.32 & 0.02 & 0.32 & 0.08 & 0.24 & -0.01 & 0.38 \\
\hline & & $(0.01)$ & $(0.02)$ & $(0.14)$ & $(0.02)$ & $(0.12)$ & $(0.02)$ & $(0.17)$ \\
\hline \multirow[t]{2}{*}{ Bolivia } & 39.69 & -0.39 & 0.23 & 1.41 & 0.11 & 1.30 & -0.79 & 1.62 \\
\hline & & $(0.05)$ & $(0.04)$ & $(0.18)$ & $(0.04)$ & $(0.13)$ & $(0.05)$ & $(0.20)$ \\
\hline \multirow[t]{2}{*}{ Botswana } & 1.24 & -7.69 & -1.21 & -10.37 & -2.04 & -8.51 & 3.53 & -11.77 \\
\hline & & $(0.05)$ & $(0.04)$ & $(0.27)$ & $(0.08)$ & $(0.35)$ & $(0.32)$ & $(0.33)$ \\
\hline \multirow[t]{2}{*}{ Brazil } & 27.10 & -0.27 & 0.00 & -0.07 & -0.23 & 0.16 & -0.26 & -0.04 \\
\hline & & $(0.01)$ & $(0.00)$ & $(0.02)$ & $(0.02)$ & $(0.01)$ & $(0.02)$ & $(0.03)$ \\
\hline \multirow[t]{2}{*}{ Bulgaria } & 4.42 & -4.02 & -1.06 & -10.04 & -1.36 & -8.80 & 0.94 & -11.03 \\
\hline & & $(0.42)$ & $(0.13)$ & $(1.27)$ & $(0.10)$ & $(1.20)$ & $(0.22)$ & (1.40) \\
\hline \multirow[t]{2}{*}{ Cambodia } & 23.14 & -0.98 & 0.07 & 0.24 & -0.40 & 0.63 & -0.55 & 0.30 \\
\hline & & $(0.06)$ & $(0.01)$ & $(0.25)$ & $(0.04)$ & $(0.28)$ & $(0.10)$ & $(0.27)$ \\
\hline \multirow[t]{2}{*}{ Cameroon } & 20.39 & -2.30 & -0.27 & -2.39 & -0.77 & -1.63 & 0.27 & -2.47 \\
\hline & & $(0.19)$ & $(0.02)$ & $(0.27)$ & $(0.01)$ & $(0.27)$ & $(0.18)$ & $(0.28)$ \\
\hline \multirow{2}{*}{ Canada } & 37.06 & -0.02 & 0.02 & 0.55 & 0.07 & 0.48 & -0.03 & 0.71 \\
\hline & & $(0.01)$ & $(0.01)$ & $(0.09)$ & $(0.01)$ & $(0.08)$ & $(0.01)$ & $(0.12)$ \\
\hline \multirow[t]{2}{*}{ Caribbean } & 15.94 & -0.50 & -0.04 & -0.48 & -0.28 & -0.19 & -0.23 & -0.53 \\
\hline & & $(0.04)$ & $(0.00)$ & $(0.06)$ & $(0.02)$ & $(0.08)$ & $(0.04)$ & $(0.08)$ \\
\hline \multirow[t]{2}{*}{ Central Africa } & 3.95 & -8.05 & -1.06 & -7.10 & -2.16 & -5.05 & 3.39 & -8.74 \\
\hline & & $(0.08)$ & $(0.03)$ & $(0.16)$ & $(0.11)$ & $(0.26)$ & $(0.39)$ & $(0.24)$ \\
\hline \multirow[t]{2}{*}{ Chile } & 40.08 & -0.67 & 0.01 & 0.12 & -0.10 & 0.22 & -0.22 & 0.14 \\
\hline & & $(0.05)$ & $(0.01)$ & $(0.06)$ & $(0.02)$ & $(0.05)$ & $(0.01)$ & $(0.07)$ \\
\hline \multirow[t]{2}{*}{ China } & 4.65 & -0.21 & 0.05 & 0.41 & -0.16 & 0.57 & -0.23 & 0.76 \\
\hline & & $(0.02)$ & $(0.00)$ & $(0.06)$ & $(0.03)$ & $(0.03)$ & $(0.02)$ & $(0.08)$ \\
\hline \multirow[t]{2}{*}{ Colombia } & 39.49 & -0.33 & 0.01 & 0.22 & -0.17 & 0.39 & -0.31 & 0.29 \\
\hline & & $(0.02)$ & $(0.01)$ & $(0.06)$ & $(0.02)$ & $(0.04)$ & $(0.01)$ & $(0.06)$ \\
\hline \multirow[t]{2}{*}{ Costa Rica } & 24.32 & -0.55 & -0.01 & -0.01 & -0.21 & 0.19 & -0.27 & 0.05 \\
\hline & & $(0.05)$ & $(0.01)$ & $(0.05)$ & $(0.02)$ & $(0.05)$ & $(0.03)$ & $(0.06)$ \\
\hline \multirow{2}{*}{ Cote d'Ivoire } & 2.96 & -4.59 & -0.73 & -4.17 & -1.54 & -2.67 & 2.18 & -5.72 \\
\hline & & $(0.46)$ & $(0.08)$ & $(0.37)$ & $(0.04)$ & $(0.34)$ & $(0.44)$ & $(0.57)$ \\
\hline \multirow[t]{2}{*}{ Croatia } & 56.71 & -1.54 & -0.18 & -1.28 & -0.30 & -0.99 & 0.16 & -1.52 \\
\hline & & $(0.22)$ & $(0.03)$ & $(0.27)$ & $(0.03)$ & $(0.24)$ & $(0.08)$ & $(0.32)$ \\
\hline \multirow[t]{2}{*}{ Cyprus } & 70.34 & 0.05 & 0.49 & 11.35 & 0.50 & 10.80 & -0.85 & 12.32 \\
\hline & & $(0.14)$ & $(0.07)$ & $(1.36)$ & $(0.07)$ & $(1.28)$ & $(0.09)$ & $(1.48)$ \\
\hline \multirow[t]{2}{*}{ Czech Republic } & 20.73 & -1.81 & -0.29 & -3.59 & -0.49 & -3.11 & 0.35 & -3.95 \\
\hline & & $(0.26)$ & 0.05 & 0.67 & 0.04 & 0.64 & 0.14 & 0.75 \\
\hline \multirow[t]{2}{*}{ Denmark } & 95.41 & -0.23 & 0.05 & 1.04 & 0.05 & 0.99 & -0.16 & 1.13 \\
\hline & & $(0.01)$ & $(0.02)$ & $(0.25)$ & $(0.03)$ & $(0.23)$ & $(0.02)$ & $(0.27)$ \\
\hline \multirow[t]{3}{*}{ Ecuador } & 16.03 & -1.36 & -0.14 & -1.10 & -0.45 & -0.65 & -0.01 & -1.21 \\
\hline & & $(0.13)$ & $(0.02)$ & $(0.16)$ & $(0.01)$ & $(0.16)$ & $(0.10)$ & $(0.19)$ \\
\hline & & Conti & d on & page & & & & \\
\hline
\end{tabular}


Table 4 - continued from previous page

\begin{tabular}{|c|c|c|c|c|c|c|c|c|}
\hline Country & $\lambda^{i}$ & $\Delta X^{i}$ & $\Delta R^{i}$ & $\Delta E^{i}$ & PSE & $\overline{\mathrm{PCE}}$ & $\Delta Y_{C}^{i}$ & $\Delta Y_{D}^{i}$ \\
\hline \multirow[t]{2}{*}{ Egypt } & -0.03 & -4.37 & -0.97 & -6.98 & -1.75 & -5.32 & 1.00 & -8.28 \\
\hline & & $(0.31)$ & $(0.09)$ & $(0.65)$ & $(0.03)$ & $(0.64)$ & $(0.32)$ & $(0.80)$ \\
\hline \multirow[t]{2}{*}{ El Salvador } & 29.40 & -0.49 & 0.04 & 0.05 & -0.18 & 0.24 & -0.28 & 0.11 \\
\hline & & $(0.04)$ & $(0.01)$ & $(0.05)$ & $(0.03)$ & $(0.03)$ & $(0.03)$ & $(0.06)$ \\
\hline \multirow[t]{2}{*}{ Estonia } & 30.63 & -1.84 & -0.26 & -2.67 & -0.40 & -2.27 & 0.10 & -2.83 \\
\hline & & $(0.22)$ & $(0.04)$ & $(0.78)$ & $(0.03)$ & $(0.75)$ & $(0.13)$ & $(0.83)$ \\
\hline \multirow[t]{2}{*}{ Ethiopia } & 7.94 & -3.66 & -0.40 & -4.05 & -1.19 & -2.89 & 1.31 & -4.82 \\
\hline & & $(0.32)$ & $(0.04)$ & $(0.36)$ & $(0.01)$ & $(0.38)$ & $(0.33)$ & $(0.46)$ \\
\hline \multirow[t]{2}{*}{ Finland } & 58.80 & -0.41 & 0.03 & 0.74 & -0.05 & 0.79 & -0.21 & 0.83 \\
\hline & & $(0.07)$ & $(0.01)$ & $(0.07)$ & $(0.01)$ & $(0.06)$ & $(0.01)$ & $(0.07)$ \\
\hline \multirow[t]{2}{*}{ France } & 147.72 & 0.37 & 0.11 & 2.18 & 0.37 & 1.80 & 0.05 & 2.93 \\
\hline & & $(0.01)$ & $(0.01)$ & $(0.21)$ & $(0.01)$ & $(0.21)$ & $(0.05)$ & $(0.30)$ \\
\hline \multirow[t]{2}{*}{ Georgia } & 24.79 & -2.45 & -0.32 & -3.23 & -0.74 & -2.51 & 0.06 & -3.54 \\
\hline & & $(0.18)$ & $(0.02)$ & $(0.48)$ & $(0.01)$ & $(0.48)$ & $(0.15)$ & $(0.54)$ \\
\hline \multirow[t]{2}{*}{ Germany } & 77.54 & -0.11 & 0.01 & 0.28 & 0.03 & 0.25 & -0.02 & 0.33 \\
\hline & & $(0.02)$ & $(0.00)$ & $(0.04)$ & $(0.01)$ & $(0.03)$ & $(0.00)$ & $(0.05)$ \\
\hline \multirow[t]{2}{*}{ Ghana } & 1.91 & -4.52 & -0.68 & -5.60 & -1.48 & -4.18 & 1.98 & -6.42 \\
\hline & & $(0.44)$ & $(0.08)$ & $(0.56)$ & $(0.03)$ & $(0.54)$ & $(0.42)$ & $(0.67)$ \\
\hline \multirow[t]{2}{*}{ Greece } & 69.81 & 1.04 & 0.82 & 12.95 & 1.20 & 11.61 & -0.31 & 13.69 \\
\hline & & $(0.15)$ & $(0.02)$ & $(0.29)$ & $(0.10)$ & $(0.19)$ & $(0.09)$ & $(0.30)$ \\
\hline \multirow[t]{2}{*}{ Guatemala } & 38.93 & -0.25 & 0.08 & 1.07 & -0.07 & 1.14 & -0.41 & 1.26 \\
\hline & & $(0.02)$ & $(0.02)$ & $(0.13)$ & $(0.03)$ & $(0.10)$ & $(0.01)$ & $(0.14)$ \\
\hline \multirow[t]{2}{*}{ Honduras } & 10.18 & -1.47 & -0.22 & -2.95 & -0.51 & -2.45 & 0.09 & -3.86 \\
\hline & & $(0.15)$ & $(0.02)$ & $(0.41)$ & $(0.01)$ & $(0.41)$ & $(0.10)$ & $(0.57)$ \\
\hline \multirow[t]{2}{*}{ Hong Kong } & -2.11 & -1.82 & -0.20 & -5.12 & -0.81 & -4.34 & 0.07 & -5.89 \\
\hline & & $(0.10)$ & $(0.02)$ & $(0.58)$ & $(0.04)$ & $(0.62)$ & $(0.17)$ & (0.69) \\
\hline \multirow[t]{2}{*}{ Hungary } & 73.21 & -0.33 & 0.13 & 1.59 & 0.12 & 1.47 & -0.29 & 2.04 \\
\hline & & $(0.08)$ & $(0.01)$ & $(0.08)$ & $(0.01)$ & $(0.07)$ & $(0.02)$ & $(0.10)$ \\
\hline \multirow[t]{2}{*}{ India } & 18.40 & -0.15 & 0.10 & 0.67 & -0.06 & 0.73 & -0.33 & 0.81 \\
\hline & & $(0.02)$ & $(0.00)$ & $(0.03)$ & $(0.01)$ & $(0.03)$ & $(0.01)$ & $(0.04)$ \\
\hline \multirow[t]{2}{*}{ Indonesia } & 2.18 & -2.32 & -0.30 & -3.31 & -1.23 & -2.10 & -0.30 & -3.90 \\
\hline & & $(0.09)$ & $(0.01)$ & $(0.05)$ & $(0.13)$ & $(0.15)$ & $(0.19)$ & $(0.08)$ \\
\hline \multirow[t]{2}{*}{ Iran } & 9.49 & -5.80 & -1.09 & -4.86 & -2.18 & -2.74 & 0.84 & -6.05 \\
\hline & & $(0.06)$ & $(0.03)$ & $(0.11)$ & $(0.08)$ & $(0.18)$ & $(0.28)$ & $(0.18)$ \\
\hline \multirow[t]{2}{*}{ Ireland } & 65.07 & -1.78 & -0.19 & -2.20 & -0.36 & -1.85 & 0.43 & -2.41 \\
\hline & & $(0.12)$ & $(0.02)$ & $(0.23)$ & $(0.02)$ & $(0.23)$ & $(0.10)$ & $(0.26)$ \\
\hline \multirow[t]{2}{*}{ Israel } & 31.06 & -0.79 & 0.01 & 0.43 & -0.28 & 0.72 & -0.41 & 0.60 \\
\hline & & $(0.07)$ & $(0.01)$ & $(0.16)$ & $(0.03)$ & $(0.19)$ & $(0.06)$ & $(0.21)$ \\
\hline \multirow[t]{2}{*}{ Italy } & 155.35 & 0.99 & 0.31 & 7.68 & 0.99 & 6.63 & 0.06 & 9.68 \\
\hline & & $(0.12)$ & $(0.01)$ & $(0.09)$ & $(0.12)$ & $(0.19)$ & $(0.14)$ & $(0.14)$ \\
\hline \multirow[t]{2}{*}{ Japan } & 48.07 & 0.76 & 0.19 & 3.72 & 0.77 & 2.93 & 0.42 & 5.34 \\
\hline & & $(0.09)$ & $(0.00)$ & $(0.02)$ & $(0.08)$ & $(0.10)$ & $(0.10)$ & $(0.07)$ \\
\hline \multirow[t]{3}{*}{ Kazakhstan } & 0.19 & -8.10 & -1.25 & -6.43 & -2.54 & -4.00 & 2.77 & -10.30 \\
\hline & & $(0.06)$ & $(0.04)$ & $(0.11)$ & $(0.12)$ & $(0.23)$ & $(0.43)$ & $(0.33)$ \\
\hline & & Contin & d on & page & & & & \\
\hline
\end{tabular}


Table 4 - continued from previous page

\begin{tabular}{|c|c|c|c|c|c|c|c|c|}
\hline Country & $\lambda^{i}$ & $\Delta X^{i}$ & $\Delta R^{i}$ & $\Delta E^{i}$ & PSE & $\mathrm{PCE}$ & $\Delta Y_{C}^{i}$ & $\Delta Y_{D}^{i}$ \\
\hline \multirow[t]{2}{*}{ Kenya } & 4.59 & -3.21 & -0.44 & -4.36 & -1.20 & -3.19 & 0.94 & -4.93 \\
\hline & & $(0.34)$ & $(0.05)$ & $(0.49)$ & $(0.02)$ & $(0.49)$ & $(0.32)$ & $(0.58)$ \\
\hline \multirow[t]{2}{*}{ Kuwait } & 0.03 & -15.08 & -3.04 & -10.22 & -4.77 & -5.72 & 6.45 & -10.64 \\
\hline & & $(0.20)$ & $(0.04)$ & $(0.12)$ & $(0.12)$ & $(0.22)$ & $(0.57)$ & $(0.13)$ \\
\hline \multirow[t]{2}{*}{ Kyrgyzstan } & 13.65 & -4.09 & -0.52 & -1.68 & -1.12 & -0.56 & 0.61 & -3.91 \\
\hline & & $(0.32)$ & $(0.04)$ & $(0.12)$ & $(0.02)$ & $(0.10)$ & $(0.28)$ & $(0.51)$ \\
\hline \multirow[t]{2}{*}{ Laos } & 13.80 & -3.08 & -0.25 & -1.82 & -0.77 & -1.06 & 0.61 & -2.52 \\
\hline & & $(0.16)$ & $(0.01)$ & $(0.09)$ & $(0.03)$ & $(0.12)$ & $(0.19)$ & $(0.17)$ \\
\hline \multirow{2}{*}{ Latvia } & 48.21 & -1.12 & -0.08 & -0.76 & -0.23 & -0.53 & -0.11 & -0.89 \\
\hline & & $(0.15)$ & $(0.02)$ & $(0.42)$ & $(0.01)$ & $(0.41)$ & $(0.09)$ & $(0.52)$ \\
\hline \multirow[t]{2}{*}{ Lithuania } & 34.77 & -1.74 & -0.28 & -2.56 & -0.48 & -2.10 & 0.19 & -3.15 \\
\hline & & $(0.22)$ & $(0.04)$ & $(0.47)$ & $(0.03)$ & $(0.44)$ & $(0.11)$ & $(0.59)$ \\
\hline \multirow[t]{2}{*}{ Luxembourg } & 107.03 & -0.45 & 0.04 & 1.70 & 0.10 & 1.60 & -0.23 & 1.77 \\
\hline & & $(0.04)$ & $(0.01)$ & $(0.12)$ & $(0.01)$ & $(0.11)$ & $(0.02)$ & $(0.13)$ \\
\hline \multirow[t]{2}{*}{ Madagascar } & 1.99 & -5.30 & -0.62 & -5.54 & -1.51 & -4.10 & 2.66 & -6.70 \\
\hline & & $(0.49)$ & $(0.07)$ & $(0.50)$ & $(0.02)$ & $(0.49)$ & $(0.48)$ & $(0.63)$ \\
\hline \multirow[t]{2}{*}{ Malawi } & 5.73 & -6.42 & -0.84 & -5.67 & -1.61 & -4.13 & 3.02 & -7.23 \\
\hline & & $(0.39)$ & $(0.05)$ & $(0.35)$ & $(0.01)$ & $(0.35)$ & $(0.39)$ & $(0.48)$ \\
\hline \multirow[t]{2}{*}{ Malaysia } & -14.40 & -6.09 & -1.19 & -11.16 & -2.65 & -8.74 & 0.95 & -13.14 \\
\hline & & $(0.12)$ & $(0.04)$ & $(0.30)$ & $(0.21)$ & $(0.49)$ & $(0.42)$ & $(0.41)$ \\
\hline \multirow[t]{2}{*}{ Malta } & 67.79 & -0.56 & 0.23 & 5.68 & 0.20 & 5.47 & -0.49 & 5.69 \\
\hline & & $(0.18)$ & $(0.10)$ & $(1.85)$ & $(0.10)$ & $(1.74)$ & $(0.12)$ & $(1.85)$ \\
\hline \multirow[t]{2}{*}{ Mauritius } & 8.36 & -3.45 & -0.52 & -5.31 & -1.09 & -4.27 & 0.83 & -5.97 \\
\hline & & $(0.24)$ & $(0.04)$ & $(0.51)$ & $(0.01)$ & $(0.52)$ & $(0.24)$ & $(0.59)$ \\
\hline \multirow[t]{2}{*}{ Mexico } & -0.19 & -0.80 & -0.10 & -1.87 & -0.48 & -1.40 & -0.17 & -1.98 \\
\hline & & $(0.09)$ & $(0.02)$ & $(0.36)$ & $(0.01)$ & $(0.37)$ & $(0.09)$ & $(0.38)$ \\
\hline \multirow[t]{2}{*}{ Mongolia } & 5.65 & -6.13 & -1.12 & -2.84 & -1.10 & -1.76 & 1.10 & -3.06 \\
\hline & & $(0.44)$ & $(0.13)$ & $(0.43)$ & $(0.09)$ & $(0.35)$ & $(0.35)$ & $(0.48)$ \\
\hline \multirow[t]{2}{*}{ Morocco } & 0.03 & -2.69 & -0.46 & -6.45 & -0.96 & -5.54 & 0.70 & -6.95 \\
\hline & & $(0.41)$ & $(0.09)$ & $(1.15)$ & $(0.06)$ & (1.11) & $(0.28)$ & $(1.25)$ \\
\hline \multirow[t]{2}{*}{ Mozambique } & 6.83 & -6.54 & -1.02 & -4.75 & -1.85 & -2.96 & 3.08 & -6.10 \\
\hline & & $(0.31)$ & $(0.06)$ & $(0.23)$ & $(0.02)$ & $(0.23)$ & $(0.40)$ & $(0.33)$ \\
\hline \multirow{2}{*}{ Namibia } & 3.36 & -3.87 & -0.65 & -7.62 & -1.24 & -6.46 & 1.12 & -9.75 \\
\hline & & $(0.20)$ & $(0.04)$ & $(0.61)$ & $(0.02)$ & $(0.63)$ & $(0.25)$ & $(0.82)$ \\
\hline \multirow[t]{2}{*}{ Nepal } & 6.23 & -2.84 & -0.30 & -3.38 & -0.89 & -2.51 & 0.82 & -5.21 \\
\hline & & $(0.27)$ & $(0.03)$ & $(0.31)$ & $(0.02)$ & $(0.33)$ & $(0.24)$ & $(0.56)$ \\
\hline \multirow[t]{2}{*}{ Netherlands } & 127.90 & 0.11 & 0.12 & 1.26 & 0.23 & 1.02 & -0.05 & 1.47 \\
\hline & & $(0.03)$ & $(0.03)$ & $(0.28)$ & $(0.03)$ & $(0.25)$ & $(0.04)$ & $(0.33)$ \\
\hline \multirow[t]{2}{*}{ New Zealand } & 0.91 & -0.83 & -0.08 & -2.04 & -0.57 & -1.48 & -0.37 & -2.44 \\
\hline & & $(0.04)$ & $(0.01)$ & $(0.29)$ & $(0.04)$ & $(0.33)$ & $(0.09)$ & $(0.38)$ \\
\hline \multirow[t]{2}{*}{ Nicaragua } & 51.56 & 0.07 & 0.46 & 3.31 & 0.30 & 3.00 & -0.96 & 4.37 \\
\hline & & $(0.04)$ & $(0.02)$ & $(0.14)$ & $(0.01)$ & $(0.13)$ & $(0.04)$ & $(0.18)$ \\
\hline \multirow[t]{3}{*}{ Nigeria } & 16.51 & -3.02 & -0.26 & -1.90 & -1.02 & -0.89 & 0.88 & -1.96 \\
\hline & & $(0.10)$ & $(0.01)$ & $(0.09)$ & $(0.03)$ & $(0.10)$ & $(0.23)$ & $(0.10)$ \\
\hline & & Contins & don & xt page & & & & \\
\hline
\end{tabular}


Table 4 - continued from previous page

\begin{tabular}{|c|c|c|c|c|c|c|c|c|}
\hline Country & $\lambda^{i}$ & $\Delta X^{i}$ & $\Delta R^{i}$ & $\Delta E^{i}$ & PSE & $\overline{\mathrm{PCE}}$ & $\Delta Y_{C}^{i}$ & $\Delta Y_{D}^{i}$ \\
\hline \multirow[t]{2}{*}{ Norway } & 148.32 & 0.23 & 0.17 & 1.59 & 0.30 & 1.29 & -0.38 & 1.66 \\
\hline & & $(0.01)$ & $(0.02)$ & $(0.14)$ & $(0.01)$ & $(0.13)$ & $(0.07)$ & $(0.15)$ \\
\hline \multirow[t]{2}{*}{ Oman } & 1.06 & -12.93 & -2.28 & -9.17 & -3.67 & -5.71 & 5.71 & -10.04 \\
\hline & & $(0.07)$ & $(0.05)$ & $(0.15)$ & $(0.09)$ & $(0.25)$ & $(0.50)$ & $(0.19)$ \\
\hline \multirow[t]{2}{*}{ Pakistan } & 41.24 & 0.33 & 0.55 & 4.36 & 0.49 & 3.85 & -0.85 & 5.14 \\
\hline & & $(0.04)$ & $(0.03)$ & $(0.19)$ & $(0.00)$ & $(0.18)$ & $(0.06)$ & $(0.22)$ \\
\hline \multirow[t]{2}{*}{ Panama } & 3.60 & -1.66 & -0.41 & -5.93 & -0.72 & -5.25 & -0.03 & -6.61 \\
\hline & & $(0.18)$ & $(0.05)$ & $(0.90)$ & $(0.02)$ & $(0.88)$ & $(0.09)$ & $(1.01)$ \\
\hline \multirow[t]{2}{*}{ Paraguay } & 42.19 & -0.69 & 0.02 & 0.39 & -0.18 & 0.57 & -0.49 & 0.41 \\
\hline & & $(0.06)$ & $(0.02)$ & $(0.04)$ & $(0.02)$ & $(0.04)$ & $(0.03)$ & $(0.04)$ \\
\hline \multirow[t]{2}{*}{ Peru } & 23.34 & -0.84 & -0.05 & -0.53 & -0.31 & -0.22 & -0.18 & -0.58 \\
\hline & & $(0.08)$ & $(0.01)$ & $(0.10)$ & $(0.01)$ & $(0.09)$ & $(0.06)$ & $(0.12)$ \\
\hline \multirow[t]{2}{*}{ Philippines } & 13.75 & -0.50 & 0.05 & -0.03 & -0.31 & 0.28 & -0.36 & 0.00 \\
\hline & & $(0.02)$ & $(0.00)$ & $(0.04)$ & $(0.04)$ & $(0.06)$ & $(0.05)$ & $(0.05)$ \\
\hline \multirow[t]{2}{*}{ Poland } & 28.79 & -0.66 & -0.04 & -0.46 & -0.17 & -0.28 & -0.12 & -0.51 \\
\hline & & $(0.14)$ & $(0.02)$ & $(0.34)$ & $(0.02)$ & $(0.32)$ & $(0.05)$ & $(0.40)$ \\
\hline \multirow[t]{2}{*}{ Portugal } & 91.63 & 0.21 & 0.22 & 4.24 & 0.32 & 3.90 & -0.30 & 5.08 \\
\hline & & $(0.03)$ & $(0.02)$ & $(0.25)$ & $(0.00)$ & $(0.25)$ & $(0.04)$ & $(0.31)$ \\
\hline \multirow[t]{2}{*}{ Qatar } & -0.05 & -8.85 & -1.45 & -10.49 & -2.88 & -7.83 & 2.75 & -11.32 \\
\hline & & $(0.11)$ & $(0.03)$ & $(0.22)$ & $(0.13)$ & $(0.34)$ & $(0.38)$ & $(0.25)$ \\
\hline \multirow[t]{2}{*}{ R.o. Central America } & 20.96 & -1.30 & -0.01 & -0.23 & -0.30 & 0.07 & -0.33 & -0.22 \\
\hline & & $(0.12)$ & $(0.01)$ & $(0.29)$ & $(0.02)$ & $(0.30)$ & $(0.13)$ & $(0.33)$ \\
\hline \multirow[t]{2}{*}{ R.o. EFTA } & 23.22 & -1.35 & -0.20 & -2.44 & -0.37 & -2.08 & 0.05 & -2.90 \\
\hline & & $(0.19)$ & $(0.03)$ & $(0.59)$ & $(0.02)$ & $(0.58)$ & $(0.10)$ & $(0.72)$ \\
\hline \multirow[t]{2}{*}{ R.o. East Asia } & 1.40 & -4.63 & -0.86 & -5.57 & -1.30 & -4.32 & 1.70 & -9.83 \\
\hline & & $(0.13)$ & $(0.04)$ & $(0.21)$ & $(0.03)$ & $(0.24)$ & $(0.20)$ & $(0.45)$ \\
\hline \multirow[t]{2}{*}{ R.o. Eastern Africa } & 1.92 & -4.47 & -0.74 & -6.06 & -1.67 & -4.47 & 1.20 & -6.93 \\
\hline & & $(0.15)$ & $(0.05)$ & $(0.35)$ & $(0.06)$ & $(0.40)$ & $(0.31)$ & $(0.42)$ \\
\hline \multirow[t]{2}{*}{ R.o. Eastern Europe } & 13.01 & -3.36 & -0.73 & -6.40 & -1.08 & -5.38 & 0.55 & -9.37 \\
\hline & & $(0.19)$ & $(0.04)$ & $(0.56)$ & $(0.03)$ & $(0.53)$ & $(0.13)$ & $(0.85)$ \\
\hline \multirow[t]{2}{*}{ R.o. Europe } & 33.62 & -0.84 & 0.00 & 0.16 & -0.12 & 0.28 & -0.21 & 0.21 \\
\hline & & $(0.13)$ & $(0.01)$ & $(0.14)$ & $(0.01)$ & $(0.13)$ & $(0.03)$ & $(0.16)$ \\
\hline \multirow[t]{2}{*}{ R.o. Form. Sov. Un. } & 2.30 & -11.16 & -2.33 & -4.48 & -3.57 & -0.94 & 5.18 & -8.10 \\
\hline & & $(0.18)$ & $(0.04)$ & $(0.02)$ & $(0.07)$ & $(0.05)$ & $(0.57)$ & $(0.19)$ \\
\hline \multirow[t]{2}{*}{ R.o. North Africa } & 0.04 & -12.76 & -2.20 & -10.81 & -3.99 & -7.10 & 5.16 & -11.99 \\
\hline & & $(0.02)$ & $(0.00)$ & $(0.69)$ & $(0.00)$ & $(0.69)$ & $(0.03)$ & $(1.14)$ \\
\hline \multirow[t]{2}{*}{ R.o. North America } & 54.27 & -0.28 & 0.03 & 4.43 & -0.09 & 4.52 & -0.31 & 7.39 \\
\hline & & $(0.20)$ & $(0.04)$ & $(0.19)$ & $(0.17)$ & $(0.36)$ & $(0.66)$ & $(0.25)$ \\
\hline \multirow[t]{2}{*}{ R.o. Oceania } & 10.34 & -2.98 & -0.41 & -4.17 & -0.94 & -3.25 & 0.48 & -5.17 \\
\hline & & $(0.03)$ & $(0.01)$ & $(0.16)$ & $(0.06)$ & $(0.22)$ & $(0.15)$ & $(0.23)$ \\
\hline \multirow[t]{2}{*}{ R.o. South Afr. C. U. } & 5.52 & -4.79 & -0.65 & -5.95 & -1.29 & -4.72 & 1.84 & -7.80 \\
\hline & & $(0.29)$ & $(0.04)$ & $(0.46)$ & $(0.01)$ & $(0.47)$ & $(0.32)$ & $(0.64)$ \\
\hline \multirow[t]{3}{*}{ R.o. South America } & 27.42 & -1.52 & -0.13 & -0.65 & -0.37 & -0.28 & -0.22 & -0.73 \\
\hline & & $(0.12)$ & $(0.01)$ & $(0.20)$ & $(0.01)$ & $(0.20)$ & $(0.11)$ & $(0.26)$ \\
\hline & & Contir & on & page & & & & \\
\hline
\end{tabular}


Table 4 - continued from previous page

\begin{tabular}{|c|c|c|c|c|c|c|c|c|}
\hline Country & $\lambda^{i}$ & $\Delta X^{i}$ & $\Delta R^{i}$ & $\Delta E^{i}$ & PSE & $\overline{\mathrm{PCE}}$ & $\Delta Y_{C}^{i}$ & $\Delta Y_{D}^{i}$ \\
\hline \multirow[t]{2}{*}{ R.o. South Asia } & 21.92 & -1.70 & -0.13 & -1.37 & -0.57 & -0.80 & -0.04 & -1.76 \\
\hline & & $(0.13)$ & $(0.01)$ & $(0.13)$ & $(0.03)$ & $(0.16)$ & $(0.13)$ & $(0.20)$ \\
\hline \multirow[t]{2}{*}{ R.o. Southeast Asia } & 19.99 & -2.47 & -0.18 & -1.01 & -0.56 & -0.45 & 0.16 & -1.33 \\
\hline & & $(0.07)$ & $(0.01)$ & $(0.05)$ & $(0.03)$ & $(0.04)$ & $(0.08)$ & $(0.07)$ \\
\hline \multirow[t]{2}{*}{ R.o. Western Africa } & 2.89 & -4.88 & -0.60 & -5.41 & -1.49 & -3.97 & 2.13 & -6.53 \\
\hline & & $(0.17)$ & $(0.04)$ & $(0.26)$ & $(0.06)$ & $(0.32)$ & $(0.34)$ & $(0.35)$ \\
\hline \multirow[t]{2}{*}{ R.o. Western Asia } & 1.77 & -8.70 & -2.14 & -8.37 & -3.39 & -5.16 & 2.55 & -9.99 \\
\hline & & $(0.12)$ & $(0.07)$ & $(0.25)$ & $(0.09)$ & $(0.33)$ & $(0.46)$ & $(0.35)$ \\
\hline \multirow[t]{2}{*}{ Romania } & 5.29 & -1.64 & -0.27 & -3.75 & -0.61 & -3.16 & 0.15 & -4.92 \\
\hline & & $(0.25)$ & $(0.05)$ & $(0.70)$ & $(0.03)$ & $(0.68)$ & $(0.14)$ & $(0.96)$ \\
\hline \multirow[t]{2}{*}{ Russia } & 25.05 & -2.50 & -0.37 & -2.36 & -0.97 & -1.41 & -0.16 & -2.47 \\
\hline & & $(0.05)$ & $(0.02)$ & $(0.12)$ & $(0.01)$ & $(0.12)$ & $(0.07)$ & $(0.13)$ \\
\hline \multirow[t]{2}{*}{ Saudi Arabia } & -0.04 & -14.51 & -2.58 & -9.37 & -4.77 & -4.83 & 4.15 & -10.15 \\
\hline & & $(0.23)$ & $(0.01)$ & $(0.05)$ & $(0.12)$ & $(0.16)$ & $(0.42)$ & $(0.08)$ \\
\hline \multirow[t]{2}{*}{ Senegal } & 12.07 & -2.28 & -0.36 & -4.07 & -0.79 & -3.30 & 0.40 & -4.33 \\
\hline & & $(0.28)$ & $(0.05)$ & $(0.58)$ & $(0.02)$ & $(0.57)$ & $(0.18)$ & $(0.63)$ \\
\hline \multirow[t]{2}{*}{ Singapore } & 5.33 & -3.46 & -0.65 & -6.27 & -1.49 & -4.85 & 0.06 & -6.31 \\
\hline & & $(0.09)$ & $(0.02)$ & $(0.19)$ & $(0.11)$ & $(0.28)$ & $(0.20)$ & $(0.19)$ \\
\hline \multirow{2}{*}{ Slovakia } & 49.15 & -0.99 & -0.06 & -0.64 & -0.17 & -0.46 & -0.04 & -0.84 \\
\hline & & $(0.16)$ & $(0.02)$ & $(0.31)$ & $(0.02)$ & $(0.29)$ & $(0.06)$ & $(0.44)$ \\
\hline \multirow[t]{2}{*}{ Slovenia } & 63.66 & -1.56 & -0.16 & -1.83 & -0.20 & -1.63 & 0.21 & -2.09 \\
\hline & & $(0.15)$ & $(0.02)$ & $(0.35)$ & $(0.01)$ & $(0.34)$ & $(0.07)$ & $(0.40)$ \\
\hline \multirow[t]{2}{*}{ South Africa } & 9.14 & -1.84 & -0.23 & -3.56 & -0.88 & -2.70 & -0.20 & -3.76 \\
\hline & & $(0.04)$ & $(0.01)$ & $(0.12)$ & $(0.09)$ & $(0.20)$ & $(0.14)$ & $(0.14)$ \\
\hline \multirow[t]{2}{*}{ South Central Africa } & 2.55 & -13.60 & -1.72 & -5.61 & -3.22 & -2.48 & 5.77 & -8.33 \\
\hline & & $(0.14)$ & $(0.03)$ & $(0.04)$ & $(0.09)$ & $(0.13)$ & $(0.56)$ & $(0.18)$ \\
\hline \multirow[t]{2}{*}{ South Korea } & 19.76 & -0.15 & 0.08 & 0.79 & -0.08 & 0.88 & -0.18 & 1.21 \\
\hline & & $(0.01)$ & $(0.00)$ & $(0.06)$ & $(0.02)$ & $(0.04)$ & $(0.01)$ & $(0.08)$ \\
\hline \multirow[t]{2}{*}{ Spain } & 63.81 & 0.13 & 0.10 & 2.95 & 0.22 & 2.72 & -0.09 & 3.48 \\
\hline & & $(0.06)$ & $(0.00)$ & $(0.05)$ & $(0.03)$ & $(0.04)$ & $(0.03)$ & $(0.06)$ \\
\hline \multirow[t]{2}{*}{ Sri Lanka } & -1.04 & -2.66 & -0.43 & -4.89 & -1.14 & -3.80 & 0.45 & -5.75 \\
\hline & & $(0.35)$ & $(0.07)$ & $(0.72)$ & $(0.03)$ & $(0.71)$ & $(0.28)$ & $(0.88)$ \\
\hline \multirow[t]{2}{*}{ Sweden } & 170.58 & 0.20 & 0.12 & 1.85 & 0.20 & 1.65 & -0.23 & 2.07 \\
\hline & & $(0.03)$ & $(0.03)$ & $(0.34)$ & $(0.03)$ & $(0.31)$ & $(0.05)$ & $(0.38)$ \\
\hline \multirow[t]{2}{*}{ Switzerland } & 120.30 & -0.21 & 0.02 & 0.39 & 0.09 & 0.30 & 0.01 & 0.56 \\
\hline & & $(0.02)$ & $(0.01)$ & $(0.12)$ & $(0.01)$ & $(0.11)$ & $(0.02)$ & (0.19) \\
\hline \multirow[t]{2}{*}{ Taiwan } & 13.81 & -0.05 & 0.17 & 3.77 & 0.05 & 3.72 & -0.25 & 4.63 \\
\hline & & $(0.03)$ & $(0.01)$ & $(0.07)$ & $(0.01)$ & $(0.06)$ & $(0.01)$ & $(0.08)$ \\
\hline \multirow[t]{2}{*}{ Tanzania } & 2.39 & -4.19 & -0.51 & -6.25 & -1.31 & -5.01 & 1.59 & -7.04 \\
\hline & & $(0.35)$ & $(0.05)$ & $(0.61)$ & $(0.01)$ & $(0.62)$ & $(0.36)$ & $(0.70)$ \\
\hline \multirow[t]{2}{*}{ Thailand } & 14.51 & -0.63 & 0.00 & 0.00 & -0.33 & 0.33 & -0.42 & 0.04 \\
\hline & & $(0.02)$ & $(0.01)$ & $(0.06)$ & $(0.04)$ & $(0.03)$ & $(0.04)$ & $(0.07)$ \\
\hline \multirow[t]{3}{*}{ Tunisia } & 1.15 & -4.76 & -0.90 & -7.70 & -1.42 & -6.36 & 1.93 & -10.71 \\
\hline & & $(0.52)$ & $(0.11)$ & $(0.93)$ & $(0.08)$ & $(0.87)$ & $(0.38)$ & $(1.34)$ \\
\hline & & Contir & on & page & & & & \\
\hline
\end{tabular}


Table 4 - continued from previous page

\begin{tabular}{lrrrrrrrr}
\hline Country & $\lambda^{i}$ & $\Delta X^{i}$ & $\Delta R^{i}$ & $\Delta E^{i}$ & PSE & PCE & $\Delta Y_{C}^{i}$ & $\Delta Y_{D}^{i}$ \\
\hline Turkey & 109.21 & 0.66 & 0.33 & 3.61 & 0.70 & 2.90 & -0.40 & 4.54 \\
& & $(0.05)$ & $(0.02)$ & $(0.16)$ & $(0.04)$ & $(0.19)$ & $(0.11)$ & $(0.22)$ \\
U.S.A. & 17.03 & 0.24 & 0.07 & 1.70 & 0.26 & 1.44 & 0.15 & 2.09 \\
& & $(0.02)$ & $(0.00)$ & $(0.06)$ & $(0.02)$ & $(0.08)$ & $(0.03)$ & $(0.08)$ \\
Uganda & 38.36 & -1.51 & -0.03 & -0.70 & -0.50 & -0.21 & -0.34 & -0.79 \\
& & $(0.10)$ & $(0.02)$ & $(0.10)$ & $(0.03)$ & $(0.12)$ & $(0.12)$ & $(0.15)$ \\
Ukraine & \multirow{2}{*}{18.66} & -2.04 & -0.43 & -2.31 & -0.77 & -1.55 & 0.00 & -2.49 \\
& & $(0.17)$ & $(0.03)$ & $(0.21)$ & $(0.02)$ & $(0.20)$ & $(0.09)$ & $(0.24)$ \\
United Arab Emirates & -0.19 & -7.00 & -1.00 & -8.04 & -2.65 & -5.53 & 1.61 & -8.15 \\
& & $(0.07)$ & $(0.03)$ & $(0.21)$ & $(0.13)$ & $(0.34)$ & $(0.40)$ & $(0.21)$ \\
United Kingdom & \multirow{2}{*}{118.50} & 0.24 & 0.09 & 1.91 & 0.27 & 1.64 & 0.00 & 2.24 \\
& & $(0.00)$ & $(0.01)$ & $(0.25)$ & $(0.01)$ & $(0.24)$ & $(0.03)$ & $(0.29)$ \\
Uruguay & \multirow{2}{*}{39.24} & -0.37 & 0.04 & 0.70 & -0.17 & 0.88 & -0.35 & 0.97 \\
& & $(0.02)$ & $(0.01)$ & $(0.05)$ & $(0.03)$ & $(0.03)$ & $(0.02)$ & $(0.06)$ \\
Venezuela & \multirow{2}{*}{7.89} & -4.21 & -0.68 & -5.59 & -1.56 & -4.09 & 0.55 & -6.08 \\
& & $(0.07)$ & $(0.02)$ & $(0.16)$ & $(0.09)$ & $(0.26)$ & $(0.23)$ & $(0.20)$ \\
Vietnam & -4.90 & -3.46 & -0.58 & -5.16 & -1.37 & -3.84 & 0.78 & -6.88 \\
& & $(0.30)$ & $(0.07)$ & $(0.56)$ & $(0.02)$ & $(0.57)$ & $(0.32)$ & $(0.82)$ \\
Zambia & \multirow{2}{*}{3.06} & -7.10 & -1.09 & -6.05 & -2.01 & -4.12 & 3.45 & -7.97 \\
& & $(0.27)$ & $(0.06)$ & $(0.26)$ & $(0.03)$ & $(0.29)$ & $(0.41)$ & $(0.39)$ \\
Zimbabwe & \multirow{2}{*}{0.25} & -8.51 & -2.00 & -9.42 & -2.75 & -6.85 & 3.76 & -11.61 \\
& & $(0.43)$ & $(0.11)$ & $(0.51)$ & $(0.05)$ & $(0.49)$ & $(0.42)$ & $(0.67)$ \\
\hline
\end{tabular}

Notes: $\lambda^{i}$ denotes the carbon tax, $\Delta X^{i}$ denotes the percentage changes in trade flows, $\Delta R^{i}$ the percentage changes in real income, $\Delta E^{i}$ the percentage changes in carbon emissions, PSE the percentage scale effect, PCE the percentage composition effect, $\Delta Y_{C}^{i}$ the percentage changes in the production in the clean sector and $\Delta Y_{D}^{i}$ the percentage changes in the production in the dirty sector. The numbers in parantheses below the reported values give the corresponding bootstrapped standard errors. 
Figure 9: Percentage Changes in Production in the Clean Sector

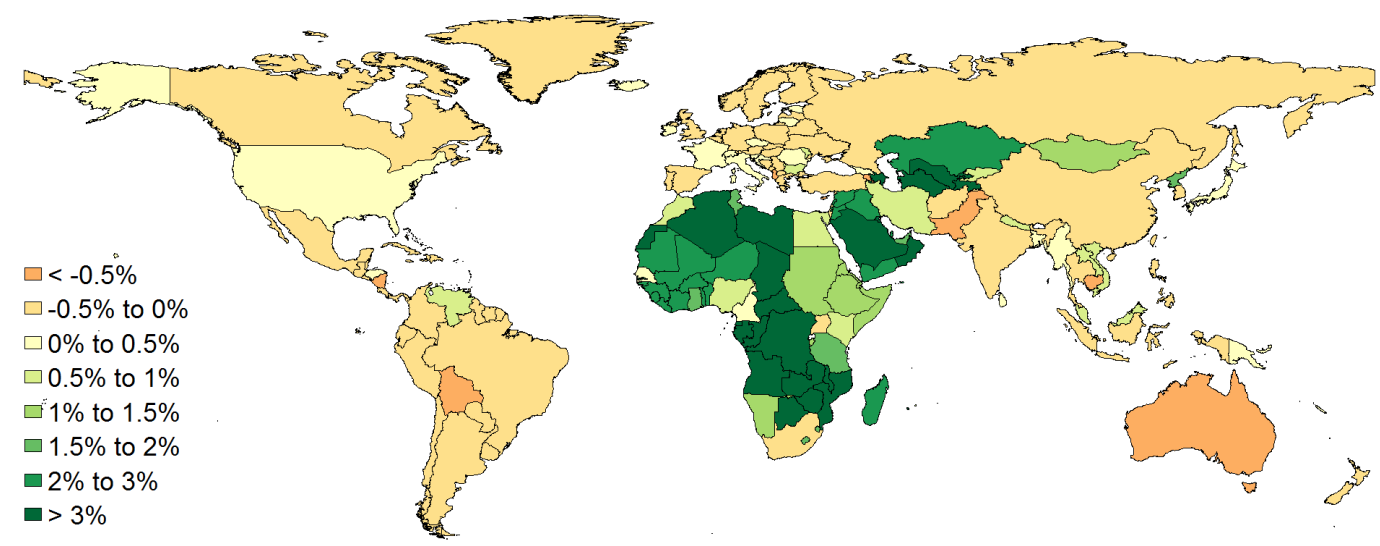

Notes: This figure shows the percentage changes in the production in the clean sector due to the counterfactual introduction of carbon tariffs. Green represents an increase in a country's production in the clean sector, while red represents a reduction. The values range between a 0.96 percent decrease for Nicaragua and a 10.78 percent increase for Azerbaijan.

Figure 10: Percentage Changes in Production in the Dirty Sector

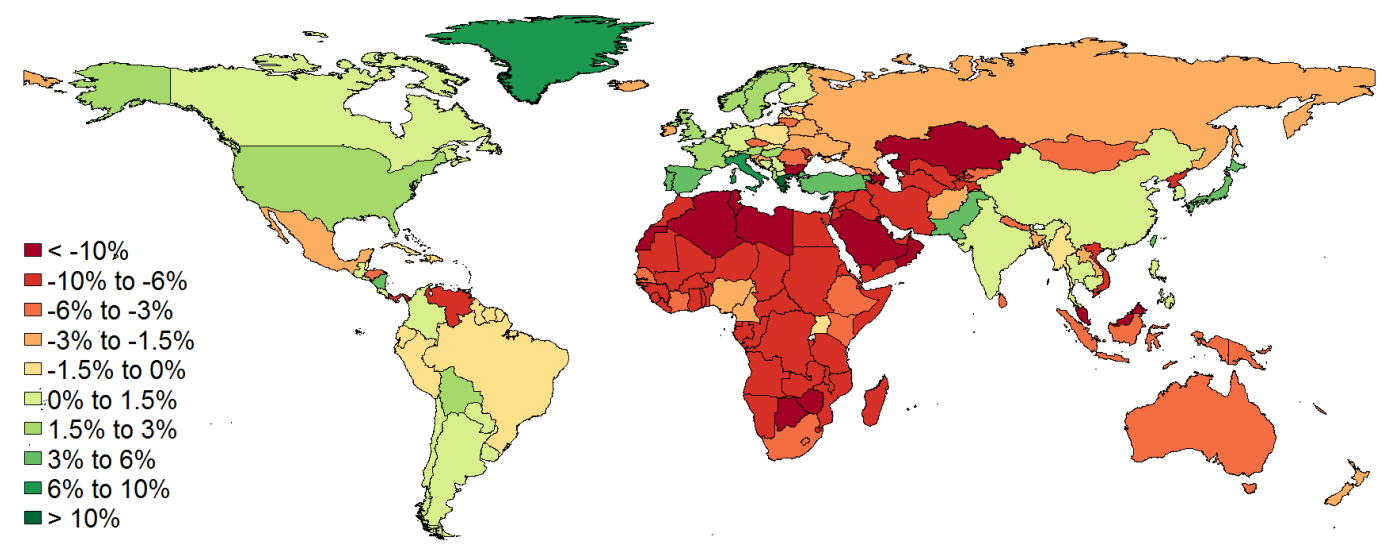

Notes: This figure shows the percentage changes in the production in the dirty sector due to the counterfactual introduction of carbon tariffs. Green represents an increase in a country's production in the dirty sector, while red represents a reduction. The values range between a 14.64 percent decrease for Bahrain and a 13.69 percent increase for Greece. 